\title{
Plantas medicinais utilizadas para o tratamento de distúrbios associados à menopausa
}

\author{
Medicinal plants used for treatment of menopause-related disorders
}

\author{
Brenda da Silva', Thailene Martins Siochetta ${ }^{2}$, Evelise Moraes Berlezi ${ }^{3 *}$
}

\begin{abstract}
${ }^{1}$ Mestrado em Associação entre a Universidade de Cruz Alta e a Universidade Regional do Noroeste do Estado do Rio Grande do Sul, Ijui - RS; ${ }^{2}$ Discente do Programa de Pós-graduação em Atenção Integral à Saúde. Mestrado em associação entre a Universidade de Cruz Alta e a Universidade Regional do Noroeste do Estado do Rio Grande do Sul, Ijuí-RS; ${ }^{3}$ Docente do Programa de Pós-graduação em Atenção Integral à Saúde. Mestrado em Associação entre a

Universidade de Cruz Alta e a Universidade Regional do Noroeste do Estado do Rio Grande do Sul, Ijuí-RS.
\end{abstract}

\begin{abstract}
Resumo
Introdução: com o aumento da expectativa de vida e o envelhecimento populacional, tendo em vista que a expectativa de vida das mulheres no Brasil é de 79,4 anos, espera-se que grande parte da população feminina passará aproximadamente um terço de suas vidas na pós-menopausa. Objetivo: sistematizar estudos científicos experimentais com modelo animal e humano que utilizaram plantas medicinais no tratamento de sintomas e patologias associadas à menopausa. Metodologia: trata-se de uma revisão bibliográfica sistemática do tipo integrativa, realizada a partir das recomendações do PRISMA, em junho de 2018, a partir de artigos publicados no período de 2014 a agosto de 2018 nas seguintes bases eletrônicas: Scielo; Pubmed; Springer; Science Direct e EBSCO, utilizando-se como palavras-chaves menopause (menopausa) e Plants, Medicinal (plantas medicinais) e seus respectivos sinônimos. Resultados: foram selecionados 453 artigos nas bases eletrônicas Scielo; Pubmed; Springer; Science Direct e EBSCO. Após leitura inicial dos títulos e resumos foram selecionados 68 artigos para análise final. Os dados coletados destes artigos foram: tipo de modelo experimental, planta utilizada, dose e tempo de tratamento, forma de apresentação, principais resultados, conclusão e local do estudo. Conclusão: as plantas medicinais parecem ser uma alternativa bastante efetiva e que apresenta poucos efeitos colaterais quando comparados à terapia de reposição hormonal. No entanto, mais estudos e ensaios clínicos são necessários para tornar estas ervas medicinais um tratamento complementar ou alternativo para o tratamento dos sintomas associados a menopausa em um futuro próximo. Palavras-chave: Terapias Complementares. Envelhecimento. Estrogênio. Terapia de Reposição Hormonal.
\end{abstract}

\begin{abstract}
Introduction: with the increase in life expectancy and population aging, considering that the life expectancy of women in Brazil is 79.4 years, it is expected that a large part of the female population will spend approximately one third of their lives in post menopause. Objective: to systematize experimental scientific studies with animal and human models that used medicinal plants to treat symptoms and pathologies associated with menopause. Methodology: this is a systematic bibliographic review of the integrative type, carried out based on the recommendations of PRISMA, in June 2018, based on articles published in the period from 2014 to August 2018 in the following electronic databases: Scielo; Pubmed; Springer; Science Direct and EBSCO, using as keywords menopause (menopause) and Plants, Medicinal (medicinal plants) and their respective synonyms. Results: 453 articles were selected from the Scielo electronic databases; Pubmed; Springer; Science Direct and EBSCO. After initial reading of the titles and Abstracts, 68 articles were selected for final analysis. The data collected from these articles were: type of experimental model, plant used, dose and treatment time, form of presentation, main results, conclusion and study location. Conclusion: medicinal plants seem to be a very effective alternative and have few side effects when compared to hormone replacement therapy.

Keywords: Complementary Therapies. Aging. Estrogen. Hormone Replacement Therapy.
\end{abstract}

\section{INTRODUÇÃO}

Com o aumento da expectativa de vida e o envelhecimento da população, tendo em vista que tal expectativa das mulheres no Brasil é de 79,4 anos ${ }^{1}$, e que a média de idade em que ocorre a menopausa é de 48,7 anos, estima-se que grande parte da população feminina passará aproximadamente um terço de suas vidas na pós-menopausa ${ }^{2}$. A menopausa é caracterizada pela perda da função ovariana marcada pela

Correpondente/Corresponding: *Evelise Moraes Berlezi- Programa de Pós-graduação em Atenção Integral à Saúde, Mestrado em associação entre a Universidade de Cruz Alta e a Universidade Regional do Noroeste do Estado do Rio Grande do Sul - End: Rua do Comércio 3000, Bairro Universitário, ljuí-RS, Brasil, CEP: 98700-000, Tel: (55) 3332-0200 - E-mail: evelise@unijui.edu.br redução dos níveis de estrogênio (E2) e progesterona, os quais estão intimamente envolvidos na homeostase de um grande número de processos fisiológicos ${ }^{3}$.

O E2 desempenha diversas funções primordiais no organismo. Dentre elas observa-se que atua na modulação da vasodilatação mediada pelo óxido nítrico, na inibição do vaso espasmo coronário, no aumento do fluxo, na redução da resistência vascular e no aumento do débito cardíaco, facilitando, assim, a angiogênese, além de desempenhar efeito apoptótico em cardiomiócitos senescentes. Outros mecanismos de proteção correspondem às ações antioxidante e anti-inflamatória, alterações benéficas no perfil lipídico, aumento da sensibilidade à insulina, atenuação do ganho de peso característico da menopausa e menor adiposidade abdominal. Após a menopausa e em virtude da cessação 
da produção de E2 pelos ovários, no entanto, este perfil protetor é perdido 4 .

A partir disto, diversas medidas terapêuticas vêm sendo estudadas com o objetivo de reduzir os efeitos da depleção de E2 durante a pós-menopausa. Uma delas é a terapia de reposição hormonal (TRH), que tem se mostrado bastante efetiva no tratamento dos distúrbios associados a este período da vida feminina ${ }^{5}$. Apesar dos seus benefícios, contudo, sabe-se que a terapia de reposição hormonal pode apresentar riscos, como ocorrência de câncer de mama, hiperplasia uterina, trombose venosa e acidente vascular cerebral $^{6}$. Emerge, então, a necessidade e a importância de se investigar formas alternativas de intervenção e tratamento dos sintomas associados à menopausa ${ }^{6}$.

Neste sentido, o uso de fitoestrógenos vem sendo estudado como uma potencial ferramenta para o manejo dos sintomas e patologias associados à menopausa. Estes são compostos não esteroides de origem vegetal que apresentam estrutura química semelhante ao E2, o que parece lhes conceder a capacidade de desempenhar função análoga ao hormônio, sendo encontrados em diversas folhas, frutas, vegetais e grãos ${ }^{7}$. Fundamentado nisso, sabe-se que o reino vegetal constitui uma fonte de novos compostos químicos que podem ser importantes por seu potencial uso medicinal, posto que a utilização de plantas com estes fins, para tratamento, cura e prevenção de doenças, é uma das mais antigas formas de prática medicinal da humanidade ${ }^{8}$. Com base nisso, objetivou-se sistematizar estudos científicos experimentais com modelo animal e humano que usaram plantas medicinais para o tratamento de sintomas e patologias associadas à menopausa. Além disso, acredita-se que um número crescente de mulheres utilize terapias complementares e alternativas para distúrbios associados à menopausa. A partir disto, estudos como este poderiam fornecer uma justificativa baseada em evidências para a escolha da terapia alternativa mais indicada e segura para cada caso.

\section{METODOLOGIA}

Trata-se de uma revisão bibliográfica sistemática do tipo integrativa realizada a partir das recomendações do Prisma (Principais Itens para Relatar Revisões Sistemáticas e Meta-análises), e está registrada no sistema International prospective register of systematic reviews (Prospero) sob o número 131968. A busca foi realizada em junho de 2018 desde artigos publicados no período de 2014 a agosto de 2018 nas seguintes bases eletrônicas: Scielo, Pubmed, Springer, Science Direct e Ebesco. Para a busca dos artigos foram utilizadas como descritores: menopause (menopausa) e Plants Medicinal (plantas medicinais) e seus respectivos sinônimos, conforme o Quadro 1.

\section{Quadro 1 - Estratégia de busca}

\begin{tabular}{|c|c|}
\hline & “Menopause"[Mesh] OR “Change of Life, Female" \\
\hline AND & $\begin{array}{l}\text { "Plants, Medicinal"[Mesh] OR “Medicinal Plant" OR "Plant, } \\
\text { Medicinal" OR "Medicinal Plants" OR "Pharmaceutical } \\
\text { Plants" OR "Pharmaceutical Plant" OR "Plant, } \\
\text { Pharmaceutical" OR “Plants, Pharmaceutical" OR “Healing } \\
\text { Plants" OR “Healing Plant" OR "Plant, Healing" OR "Plants, } \\
\text { Healing" OR "Medicinal Herbs" OR "Herb, Medicinal" OR } \\
\text { "Medicinal Herb" OR "Herbs, Medicinal" }\end{array}$ \\
\hline
\end{tabular}

Fonte: Autoria própria
Os artigos identificados pela estratégia de busca foram avaliados por dois pesquisadores de forma independente, e na primeira etapa da revisão selecionou-se os artigos conforme os seguintes critérios de elegibilidade: estudos experimentais com modelo animal e humano de menopausa, publicados em todos os idiomas no período de 2014 a 2018 nas bases Scielo, Pubmed, Springer, Science Direct e Ebesco. Foram estabelecidos os seguintes critérios de exclusão: artigos repetidos, artigos de revisão, artigos que utilizassem metodologia in vitro, com delineamento observacional, e publicações em anais de eventos. Os artigos divergentes entre os avaliadores foram analisados novamente pelos mesmos até chegarem a um acordo sobre a inclusão ou exclusão. Após o consenso dos dois pesquisadores quanto aos artigos selecionados, foi feita a extração dos dados (Figura 1).

\section{Figura 1 - Fluxograma de seleção dos artigos pesquisados}

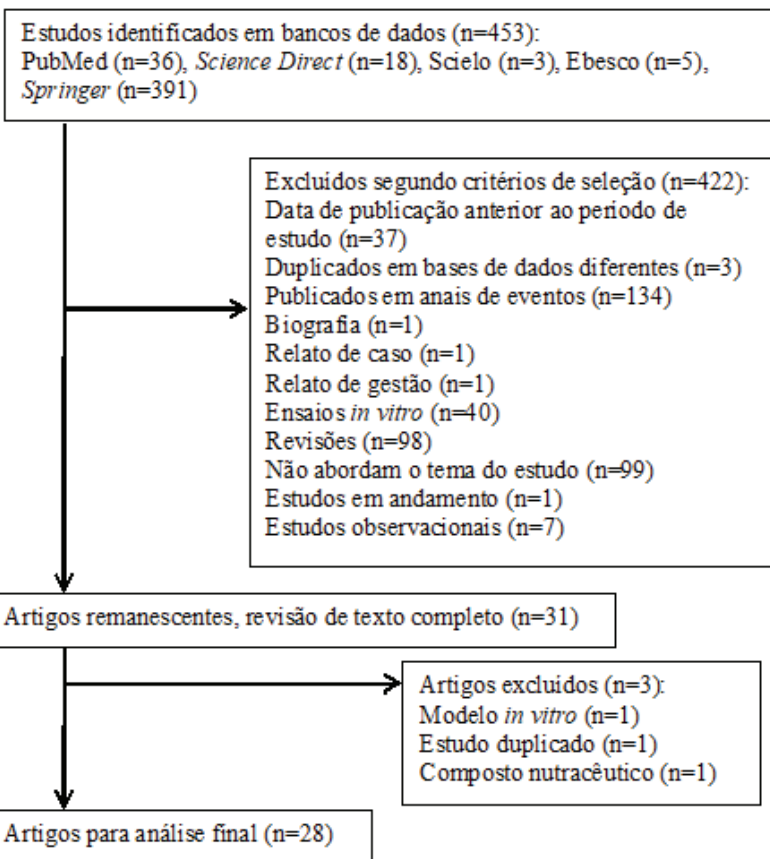

Fonte: Dados da pesquisa

Durante a compilação de dados foi enfatizada a busca pelas seguintes informações: objetivo do estudo, tipo de modelo experimental, planta utilizada, dose e tempo de tratamento, forma de apresentação do tratamento, resultados e conclusão.

\section{RESULTADOS}

Foram selecionados 453 artigos nas bases eletrônicas Scielo, Pubmed, Springer, Science Direct e Ebesco. Após leitura inicial dos pesquisadores, selecionou-se 28 artigos para análise final. Os processos realizados na seleção dos artigos e os motivos de exclusão estão descritos na Figura 1.

Na extração dos dados dos artigos selecionados, realizada pelos pesquisadores, priorizou-se a busca pelos objetivos do estudo, modelo experimental, planta utilizada, dose e tempo de tratamento, forma de apresentação do tratamento, resultados, conclusão, utilidade investigada e local do estudo (Quadro 2). 
Quadro 2 - Sumário dos estudos encontrados e suas variáveis de interesse

\begin{tabular}{|c|c|c|c|c|c|c|c|c|c|c|c|c|}
\hline Título & Autor & $\begin{array}{l}\text { Local do } \\
\text { estudo }\end{array}$ & Espécie & $\begin{array}{l}\text { Delineamento } \\
\text { experimental }\end{array}$ & $\begin{array}{c}\text { Modelo } \\
\text { experimental }\end{array}$ & \begin{tabular}{|c|} 
Tempo de \\
tratamento
\end{tabular} & $\begin{array}{l}\text { Dose e forma de } \\
\text { apresentação do } \\
\text { composto }\end{array}$ & $\begin{array}{c}\text { Objetivo do } \\
\text { trabalho }\end{array}$ & Principais resultados & Conclusão & $\begin{array}{l}\text { Utilização } \\
\text { investigada }\end{array}$ & $\begin{array}{l}\text { Base de } \\
\text { dados }\end{array}$ \\
\hline \multicolumn{13}{|c|}{ Ensaios Clínicos } \\
\hline $\begin{array}{l}\text { Effect of Foeniculum } \\
\text { vulgare Mill. (fennel) on } \\
\text { menopausal symptoms in } \\
\text { postmenopausal women: } \\
\text { a randomized, triple- } \\
\text { blind, placebo-controlled } \\
\text { trial. }\end{array}$ & $\begin{array}{l}\text { Rahimikian et } \\
\text { al.,2017 }\end{array}$ & |Irã & \begin{tabular}{|l}
$\begin{array}{l}\text { Foeniculum } \\
\text { vulgare }\end{array}$ \\
\end{tabular} & $\begin{array}{l}\text { Ensaio triplo-cego, } \\
\text { controlado por } \\
\text { placebo. }\end{array}$ & $\begin{array}{l}\text { Mulheres } \\
\text { menopausadas. }\end{array}$ & 8 semanas & \begin{tabular}{|l}
$100 \mathrm{mg}$ em \\
Cápsulas \\
gelatinosas 2/dia.
\end{tabular} & $\begin{array}{l}\text { Avaliar a eficácia } \\
\text { do Foeniculum } \\
\text { vulgare no manejo } \\
\text { dos sintomas da } \\
\text { menopausa em } \\
\text { mulheres na pós- } \\
\text { menopausa. }\end{array}$ & $\begin{array}{l}\text { Redução significativa } \\
\text { no escore médio de } \\
\text { gravidade dos sintomas } \\
\text { da menopausa. }\end{array}$ & $\begin{array}{l}\text { O Foeniculum } \\
\text { vulgare é um } \\
\text { tratamento eficaz e } \\
\text { seguro para reduzir } \\
\text { os sintomas da } \\
\text { menopausa em } \\
\text { mulheres na pós- } \\
\text { menopausa sem } \\
\text { efeitos colaterais } \\
\text { graves. }\end{array}$ & \multirow[t]{2}{*}{ Atrofia vaginal. } & \multirow[t]{2}{*}{ Pubmed } \\
\hline $\begin{array}{l}\text { Effect of Foeniculum } \\
\text { vulgare (fennel) vaginal } \\
\text { cream on vaginal atrophy } \\
\text { in postmenopausal } \\
\text { women: A double-blind } \\
\text { randomized placebo- } \\
\text { controlled trial. }\end{array}$ & $\begin{array}{l}\text { Yaralizadeh et } \\
\text { al.2016 }\end{array}$ & |Irã & $\begin{array}{l}\text { Foeniculum } \\
\text { vulgar }\end{array}$ & \begin{tabular}{|l|} 
Ensaio duplo-cego \\
randomizado \\
controlado por \\
placebo.
\end{tabular} & $\begin{array}{l}\text { Mulheres } \\
\text { menopausadas. }\end{array}$ & 8 semanas & $\begin{array}{l}\text { 5g/dia, creme } \\
\text { vaginal } 5 \% .\end{array}$ & $\begin{array}{l}\text { Investigar o efeito } \\
\text { do creme vaginal } \\
\text { de Foeniculum } \\
\text { vulgare na atrofia } \\
\text { vaginal em } \\
\text { mulheres na pós- } \\
\text { menopausa. }\end{array}$ & $\begin{array}{l}\text { Aumento do número } \\
\text { de células superficiais, } \\
\text { redução do número de } \\
\text { células intermediárias } \\
\text { e parabasais e do pH } \\
\text { vaginal. }\end{array}$ & $\begin{array}{l}\text { O Foeniculum } \\
\text { vulgare é um meio } \\
\text { eficaz para controlar } \\
\text { os sintomas da } \\
\text { atrofia vaginal } \\
\text { em mulheres na } \\
\text { pós-menopausa e } \\
\text { é desprovido de } \\
\text { efeitos colaterais. }\end{array}$ & & \\
\hline $\begin{array}{l}\text { Bioavailability of } \\
\text { phenolics from an } \\
\text { oleuropein-rich olive } \\
\text { (Olea europaea) leaf } \\
\text { extract and its acute } \\
\text { effect on plasma } \\
\text { antioxidant status: } \\
\text { comparison between pre } \\
\text { - and postmenopausal } \\
\text { women }\end{array}$ & $\begin{array}{l}\text { Garcia-Villalba et } \\
\text { al.2014 }\end{array}$ & Espanha & Olea europea & Experimental. & $\begin{array}{l}\text { Mulheres na pré e } \\
\text { pós-menopausa. }\end{array}$ & $\begin{array}{l}1 \text { única } \\
\text { ingestão }\end{array}$ & $\begin{array}{l}\text { Extrato metanólico } \\
\text { das folhas na } \\
\text { dose de } 250 \\
\text { mg, cápsulas } \\
\text { gelatinosas }\end{array}$ & $\begin{array}{l}\text { Investigar a } \\
\text { biodisponibilidade } \\
\text { oral de um } \\
\text { extrato de folhas } \\
\text { de oliveira rico } \\
\text { em oleuropeína } \\
\text { (40\%) e seu efeito } \\
\text { sobre o estado } \\
\text { antioxidante em } \\
\text { mulheres na pós- } \\
\text { menopausa. } \\
\end{array}$ & \begin{tabular}{|l} 
Redução da \\
peroxidação lipídica \\
em mulheres na pós- \\
menopausa.
\end{tabular} & $\begin{array}{l}\text { O tratamento } \\
\text { demonstra potencial } \\
\text { para melhora } \\
\text { de processos } \\
\text { relacionados à } \\
\text { idade e ao estresse } \\
\text { oxidativo, como } \\
\text { a osteoporose na } \\
\text { menopausa. }\end{array}$ & Osteoporose & \multirow{2}{*}{ Springer } \\
\hline $\begin{array}{l}\text { Effect of fennel vaginal } \\
\text { cream on sexual function } \\
\text { in postmenopausal } \\
\text { women: A double blind } \\
\text { randomized controlled } \\
\text { trial. }\end{array}$ & Abedi et al. 2018 & Irã & $\begin{array}{l}\text { Pimpinella } \\
\text { anisum }\end{array}$ & $\begin{array}{l}\text { Ensaio Clínico } \\
\text { Randomizado e } \\
\text { controlado por } \\
\text { placebo. }\end{array}$ & $\begin{array}{l}\text { Mulheres na pós- } \\
\text { menopausa com } \\
\text { disfunção sexual. }\end{array}$ & 8 semanas & $\begin{array}{l}5 \mathrm{~g} / \mathrm{dia} \text {, creme } \\
\text { vaginal }\end{array}$ & $\begin{array}{l}\text { Avaliar o efeito } \\
\text { do funcho sobre a } \\
\text { função sexual em } \\
\text { mulheres na pós- } \\
\text { menopausa. }\end{array}$ & \begin{tabular}{|l} 
Todas as áreas \\
da função sexual, \\
incluindo excitação, \\
lubrificação, orgasmo, \\
satisfação sexual e dor \\
melhoraram nos grupos \\
tratado e placebo \\
além do escore total \\
do Índice de Função \\
Sexual Feminina \\
após 8 semanas de \\
tratamento. \\
\end{tabular} & \begin{tabular}{|l} 
O creme vaginal de \\
Pimpinella anisum \\
é um meio eficaz de \\
melhorar a atividade \\
sexual em mulheres \\
na pós-menopausa.
\end{tabular} & $\begin{array}{l}\text { Disfunção } \\
\text { sexual. }\end{array}$ & \\
\hline
\end{tabular}


Brenda da Silva, Thailene Martins Siochetta, Evelise Moraes Berlezi

\begin{tabular}{|c|c|c|c|c|c|c|c|c|c|c|c|c|}
\hline Título & Autor & $\begin{array}{l}\text { Local do } \\
\text { estudo }\end{array}$ & Espécie & $\begin{array}{l}\text { Delineamento } \\
\text { experimental }\end{array}$ & $\begin{array}{c}\text { Modelo } \\
\text { experimental }\end{array}$ & $\begin{array}{l}\text { Tempo de } \\
\text { tratamento }\end{array}$ & $\begin{array}{l}\text { Dose e forma de } \\
\text { apresentação do } \\
\text { composto }\end{array}$ & $\begin{array}{l}\text { Objetivo do } \\
\text { trabalho }\end{array}$ & Principais resultados & Conclusão & $\begin{array}{c}\text { Utilização } \\
\text { investigada }\end{array}$ & $\begin{array}{c}\text { Base de } \\
\text { dados }\end{array}$ \\
\hline \multicolumn{13}{|c|}{ Ensaios Clínicos } \\
\hline $\begin{array}{l}\text { Danshen enhanced } \\
\text { the estrogenic effects } \\
\text { of Qing E formula in } \\
\text { ovariectomized rats }\end{array}$ & Zhang et al. 2016 & China & \begin{tabular}{|l|} 
Eucommia \\
ulmoides, \\
Psoraleae \\
fructus, Salvia \\
miltiorrhiza
\end{tabular} & Experimental. & \begin{tabular}{|l} 
Ratos Sprague- \\
Dawley \\
ovariectomizados.
\end{tabular} & 12 semanas & $\begin{array}{l}\text { Quing E } 250 \text { e } \\
500 \mathrm{mg} / \mathrm{kg} / \mathrm{dia} \text {, } \\
\text { BDD } 1815 \mathrm{mg} / \mathrm{kg}, \\
\text { extrato aquoso }\end{array}$ & \begin{tabular}{|l|} 
Avaliar os efeitos \\
sinérgicos de \\
Danshen (Sálvia \\
miltiorrhiza \\
bunge) e os efeitos \\
fitoestrogênicos \\
de três fórmulas \\
modificadas de \\
Qing E, para \\
explorar uma \\
fórmula melhor \\
para distúrbios da \\
menopausa.
\end{tabular} & $\begin{array}{l}\text { O tratamento } \\
\text { aumentou o peso } \\
\text { e a parede uterina, } \\
\text { epitélio endometrial e } \\
\text { epitélio glandular, osso } \\
\text { trabecular melhorado } \\
\text { e densidade total, } \\
\text { evidentemente, reduziu } \\
\text { os níveis de lipídios } \\
\text { plasmáticos. }\end{array}$ & $\begin{array}{l}\text { Fórmula Qing E mais } \\
\text { Danshen exerceram } \\
\text { efeitos estrogênicos } \\
\text { mais evidentes } \\
\text { do que outros } \\
\text { grupos na melhoria } \\
\text { da estrutura dos } \\
\text { órãos-alvo de } \\
\text { estrogênio, como } \\
\text { útero e osso, e } \\
\text { modulação do } \\
\text { metabolismo } \\
\text { endócrino. }\end{array}$ & $\begin{array}{l}\text { Osteoporose e } \\
\text { dislipidemias }\end{array}$ & \multirow{3}{*}{ Springer } \\
\hline $\begin{array}{l}\text { Efficacy of Crocus sativus } \\
\text { (saffron) in treatment } \\
\text { of major depressive } \\
\text { disorder associated with } \\
\text { post-menopausal hot } \\
\text { flashes: a double-blind, } \\
\text { randomized, placebo- } \\
\text { controlled trial }\end{array}$ & Kashani et al. 2018 & |rã & Crocus sativus & Experimental. & $\begin{array}{l}\text { Mulheres com } \\
\text { ondas de calor na } \\
\text { pós-menopausa. }\end{array}$ & 6 semanas & $\begin{array}{l}15 \text { e } 30 \mathrm{mg} \text { em } \\
\text { cápsulas, duas } \\
\text { vezes por dia }\end{array}$ & $\begin{array}{l}\text { Avaliar a eficácia } \\
\text { e segurança } \\
\text { do estigma de } \\
\text { Crocus sativus } \\
\text { no tratamento } \\
\text { do transtorno } \\
\text { depressivo maior } \\
\text { associado a ondas } \\
\text { de calor pós- } \\
\text { menopausa. }\end{array}$ & $\begin{array}{l}\text { Efeito de interação } \\
\text { entre o tempo x } \\
\text { tratamento na Escala } \\
\text { de Interferência Diária } \\
\text { Relacionada ao Flash e } \\
\text { Escala de Depressão de } \\
\text { Hamilton. }\end{array}$ & $\begin{array}{l}\text { O tratamento é } \\
\text { eficaz na melhora } \\
\text { das ondas de } \\
\text { calor e sintomas } \\
\text { depressivos em } \\
\text { mulheres saudáveis } \\
\text { pós-menopausadas. }\end{array}$ & Ondas de calor & \\
\hline $\begin{array}{l}\text { A randomised controlled } \\
\text { trial on hypolipidemic } \\
\text { effects of Nigella } \\
\text { Sativa seeds powder in } \\
\text { menopausal women }\end{array}$ & Ibrahim et al. 2014 & Malásia & Nigella sativa & \begin{tabular}{|l|} 
Estudo \\
randomizado \\
controlado por \\
placebo.
\end{tabular} & $\begin{array}{l}\text { Mulheres na pós- } \\
\text { menopausa com } \\
\text { risco moderado de } \\
\text { hiperlipidemia. }\end{array}$ & 8 semanas & $\begin{array}{l}1 \mathrm{~g} / \text { dia, pó das } \\
\text { sementes }\end{array}$ & $\begin{array}{l}\text { Avaliar os efeitos } \\
\text { hipolipidêmicos } \\
\text { da } N \text {. sativa } \text { em } \\
\text { mulheres na } \\
\text { menopausa. }\end{array}$ & $\begin{array}{l}\text { Redução significativa } \\
\text { da dislipidemia e } \\
\text { discreto aumento no } \\
\text { HDL entre mulheres } \\
\text { na menopausa. Além } \\
\text { disto, a planta também } \\
\text { pode melhorar glicemia } \\
\text { e pressão arterial } \\
\text { em mulheres na } \\
\text { menopausa. }\end{array}$ & \begin{tabular}{|l} 
Niguella sativa \\
melhorou \\
significativamente \\
o perfil lipídico \\
de mulheres na \\
menopausa.
\end{tabular} & Dislipidemia & \\
\hline
\end{tabular}


Plantas medicinais utilizadas para o tratamento de distúrbios associados à menopausa

\begin{tabular}{|c|c|c|c|c|c|c|c|c|c|c|c|c|}
\hline Título & Autor & $\begin{array}{l}\text { Local do } \\
\text { estudo }\end{array}$ & Espécie & $\begin{array}{l}\text { Delineamento } \\
\text { experimental }\end{array}$ & $\begin{array}{c}\text { Modelo } \\
\text { experimental }\end{array}$ & \begin{tabular}{|c|} 
Tempo de \\
tratamento
\end{tabular} & $\begin{array}{l}\text { Dose e forma de } \\
\text { apresentação do } \\
\text { composto }\end{array}$ & $\begin{array}{c}\text { Objetivo do } \\
\text { trabalho }\end{array}$ & Principais resultados & Conclusão & $\begin{array}{c}\text { Utilização } \\
\text { investigada }\end{array}$ & $\begin{array}{l}\text { Base de } \\
\text { dados }\end{array}$ \\
\hline \multicolumn{13}{|c|}{ Ensaios Experimentais } \\
\hline $\begin{array}{l}\text { The combination of } \\
\text { Artemisia princeps Pamp, } \\
\text { Leonurus japonicas Houtt, } \\
\text { and Gardenia jasminoides } \\
\text { Ellis fruit attenuates } \\
\text { the exacerbation of } \\
\text { energy, lipid, and glucose } \\
\text { by increasing hepatic } \\
\text { PGC-1 } 1 \text { expression in } \\
\text { estrogen-deficient rats }\end{array}$ & Yang et al. 2016 & Coreia. & \begin{tabular}{|l} 
Artemisia \\
princeps, \\
Leonurus \\
japonicas \\
e Gardenia \\
jasminoides
\end{tabular} & Experimental. & \begin{tabular}{|l|} 
Ratas Sprague- \\
Dawley \\
ovariectomizadas, \\
alimentadas com \\
dieta hiperlipídica.
\end{tabular} & 8 semanas & $\begin{array}{l}3 \text { a } 5 g / \text { dia, extrato } \\
\text { aquoso } \\
\\
\end{array}$ & $\begin{array}{l}\text { Avaliar se a } \\
\text { combinação } \\
\text { destas plantas } \\
\text { possui potencial } \\
\text { para reduzir os } \\
\text { níveis de glicose, } \\
\text { lipídios e melhorar } \\
\text { o metabolismo } \\
\text { ósseo causado } \\
\text { pela deficiência de } \\
\text { estrogênio. }\end{array}$ & $\begin{array}{l}\text { O tratamento melhorou } \\
\text { o metabolismo } \\
\text { energético e atenuou } \\
\text { uma diminuição no } \\
\text { gasto de energia na } \\
\text { mesma quantidade } \\
\text { que o estrogênio. Além } \\
\text { disso, reduziu a gordura } \\
\text { visceral e intramuscular } \\
\text { e aumentou a } \\
\text { massa corporal } \\
\text { magra, melhorou a } \\
\text { dislipidemia, níveis } \\
\text { séricos de insulina, } \\
\text { os níveis séricos de } \\
\text { glicose, resistência à } \\
\text { insulina, aumentou } \\
\text { o número de genes } \\
\text { envolvidos na oxidação } \\
\text { de ácidos graxos e } \\
\text { diminuiu a síntese de } \\
\text { ácidos graxos. }\end{array}$ & \begin{tabular}{|l|} 
Melhora da \\
dislipidemia e \\
da intolerância à \\
glicose, inibição do \\
gasto energético, \\
da oxidação dos \\
ácidos graxos e da \\
resistência à insulina, \\
potencializaram \\
a expressão de \\
PGC-1a no fígado \\
e melhoraram \\
a tolerância \\
à glicose no \\
modelo estudado. \\
Além de inibir a \\
gliconeogênese no \\
estado alimentado.
\end{tabular} & Dislipidemia & \multirow[t]{2}{*}{ Springer } \\
\hline $\begin{array}{l}\text { Miroestrol, a } \\
\text { phytoestrogen from } \\
\text { Pueraria mirifica, } \\
\text { improves the } \\
\text { antioxidation state in } \\
\text { the livers and uteri of } \\
\beta \text {-naphthoflavone-treated } \\
\text { mice }\end{array}$ & $\begin{array}{l}\text { Jearapong et al. } \\
2014 \\
\end{array}$ & Tailândia & $\begin{array}{l}\text { Pueraria } \\
\text { candollei }\end{array}$ & & Camundongos ICR & 7 dias & \begin{tabular}{|l|}
0,5 e $5 \mathrm{mg} / \mathrm{kg} / \mathrm{dia}$ \\
de $\beta$-naftoflavona \\
por via subcutânea
\end{tabular} & \begin{tabular}{|l} 
Investigar as \\
atividades \\
de enzimas \\
antioxidantes \\
e os níveis de \\
peroxidação \\
lipídica nos \\
fígados e útero \\
de camundongos \\
tratados com \\
ß-naftoflavona.
\end{tabular} & $\begin{array}{l}\text { Melhora da capacidade } \\
\text { antioxidante hepática } \\
\text { e uterina. No fígado, o } \\
\text { tratamento aumentou } \\
\text { os níveis de várias } \\
\text { formas de glutationa, } \\
\text { enquanto no útero o } \\
\text { Miroestrol reduziu o } \\
\text { nível de peroxidação } \\
\text { lipídica. }\end{array}$ & \begin{tabular}{|l|} 
O uso de Miroestrol \\
como alternativa \\
terapêutica de \\
reposição hormonal \\
pode ser benéfico \\
devido a sua \\
capacidade de \\
melhorar os sistemas \\
antioxidantes.
\end{tabular} & $\begin{array}{l}\text { Efeito } \\
\text { antioxidante. }\end{array}$ & \\
\hline $\begin{array}{l}\text { Effect of miroestrol on } \\
\text { ovariectomy-induced } \\
\text { cognitive impairment } \\
\text { and lipid peroxidation in } \\
\text { mouse brain }\end{array}$ & $\begin{array}{l}\text { Monthakantirat et } \\
\text { al .2014 }\end{array}$ & Tailândia. & $\begin{array}{l}\text { Pueraria } \\
\text { candollei }\end{array}$ & Experimental. & \begin{tabular}{|l|} 
Camundongos \\
ovariectomizados.
\end{tabular} & 8 semanas & $\begin{array}{l}0.1 \text { e } 1 \mathrm{mg} / \mathrm{kg}, \\
\text { miroesterol por via } \\
\text { intraperitoneal. } \\
\\
\end{array}$ & $\begin{array}{l}\text { Avaliar os efeitos } \\
\text { do Miroestrol } \\
\text { na função } \\
\text { cognitiva, dano } \\
\text { oxidativo cerebral } \\
\text { e expressão } \\
\text { de genes que } \\
\text { codificam fator } \\
\text { neurotrófico } \\
\text { derivado do } \\
\text { cérebro (BDNF) e } \\
\text { proteína de ligação } \\
\text { ao elemento } \\
\text { responsivo ao } \\
\text { AMP cíclico. }\end{array}$ & $\begin{array}{l}\text { Redução da disfunção } \\
\text { cognitiva induzida } \\
\text { pela ovariectomia. O } \\
\text { tratamento reverteu } \\
\text { significativamente } \\
\text { as alterações de } \\
\text { estresse oxidativo } \\
\text { neuroquímicas } \\
\text { causadas pelo } \\
\text { procedimento. }\end{array}$ & $\begin{array}{l}\text { O composto melhora } \\
\text { os déficts cognitivos } \\
\text { em animais } \\
\text { ovariectomizados. }\end{array}$ & $\mid$\begin{tabular}{|l} 
Efeito \\
neuroprotetor.
\end{tabular} & $\begin{array}{l}\text { Science } \\
\text { Direct }\end{array}$ \\
\hline
\end{tabular}


Brenda da Silva, Thailene Martins Siochetta, Evelise Moraes Berlezi

\begin{tabular}{|c|c|c|c|c|c|c|c|c|c|c|c|c|}
\hline Título & Autor & $\begin{array}{l}\text { Local do } \\
\text { estudo }\end{array}$ & Espécie & $\begin{array}{l}\text { Delineamento } \\
\text { experimental }\end{array}$ & $\begin{array}{c}\text { Modelo } \\
\text { experimental }\end{array}$ & \begin{tabular}{|l|} 
Tempo de \\
tratamento
\end{tabular} & $\begin{array}{l}\text { Dose e forma de } \\
\text { apresentação do } \\
\text { composto }\end{array}$ & $\begin{array}{c}\text { Objetivo do } \\
\text { trabalho }\end{array}$ & Principais resultados & Conclusão & $\begin{array}{c}\text { Utilização } \\
\text { investigada }\end{array}$ & $\begin{array}{l}\text { Base de } \\
\text { dados }\end{array}$ \\
\hline \multicolumn{13}{|c|}{ Ensaios Experimentais } \\
\hline $\begin{array}{l}\text { Estrogen-like and } \\
\text { tissue-selective effects } \\
\text { of 7-methoxycoumarin } \\
\text { from Ficus umbellata } \\
\text { (Moraceae): an in vitro } \\
\text { and in vivo study }\end{array}$ & Zingue et al. 2017 & Camarões & \begin{tabular}{|l|} 
Ficus umbellata \\
\end{tabular} & Experimental. & $\begin{array}{l}\text { Ratos Wistar } \\
\text { ovariectomizados. }\end{array}$ & 3 dias & \begin{tabular}{|l|}
$10 \mathrm{mg} / \mathrm{kg}$ \\
7 -metoxicumarina \\
isolada do extrato \\
metanólico
\end{tabular} & $\begin{array}{l}\text { Avaliar os efeitos } \\
\text { estrogênicos/ } \\
\text { antiestrogênicos } \\
\text { do } \\
\text { 7-metoxicumarina } \\
\text { in vivo. }\end{array}$ & $\begin{array}{l}\text { O tratamento } \\
\text { induziu um aumento } \\
\text { significativo da altura } \\
\text { do epitélio vaginal. } \\
\text { Nenhuma mudança } \\
\text { significativa foi } \\
\text { observada em relação } \\
\text { ao peso de gordura } \\
\text { abdominal, os níveis de } \\
\text { lipídios séricos e peso } \\
\text { ósseo. }\end{array}$ & $\begin{array}{l}\text { O tratamento possui } \\
\text { uma fraca atividade } \\
\text { estrogênica in vitro e } \\
\text { in vivo. Podendo ser } \\
\text { benéfico no que diz } \\
\text { respeito à secura da } \\
\text { vagina. }\end{array}$ & $\begin{array}{l}\text { Efeitos } \\
\text { estrogênicos }\end{array}$ & \multirow{3}{*}{ Springer } \\
\hline $\begin{array}{l}\text { Soyo-san reduces } \\
\text { depressive-like behavior } \\
\text { and proinflammatory } \\
\text { cytokines in } \\
\text { ovariectomized female } \\
\text { rats }\end{array}$ & Park et al. 2014 & $\begin{array}{l}\text { República } \\
\text { da Coreia. }\end{array}$ & \begin{tabular}{|l|} 
Paeoliae \\
radix alba, \\
Atractylodis \\
macrocephalae \\
phizoma, \\
Angelicae \\
gigantis radix, \\
Poria, Liriopis \\
tuber, Bupleuri \\
radix, Menthae \\
herba, \\
Glycyrrhizae \\
radix e Zingiberi \\
rhizoma recens. \\
\end{tabular} & \begin{tabular}{|l} 
Experimental. \\
\\
\end{tabular} & \begin{tabular}{|l} 
Ratas Sprague \\
Dawley
\end{tabular} & 2 semanas & $\begin{array}{l}100 \text { e } 400 \mathrm{mg}, \\
\text { extrato aquoso. }\end{array}$ & $\begin{array}{l}\text { Investigar se a } \\
\text { administração de } \\
\text { soja-san é capaz } \\
\text { de modular o } \\
\text { comportamento } \\
\text { depressivo e a } \\
\text { produção de } \\
\text { citocinas pró- } \\
\text { inflamatórias } \\
\text { em um modelo } \\
\text { animal. }\end{array}$ & $\begin{array}{l}\text { Melhora do estado } \\
\text { depressivo e redução } \\
\text { de marcadores pró- } \\
\text { inflamatórios. No } \\
\text { cérebro, a expressão } \\
\text { de neurônios } \\
\text { positivos para IL-1ß } \\
\text { no grupo controle foi } \\
\text { significativamente } \\
\text { aumentada no núcleo } \\
\text { paraventricular } \\
\text { e hipocampo em } \\
\text { comparação com os } \\
\text { não tratados. }\end{array}$ & $\begin{array}{l}\text { O composto reduz } \\
\text { efetivamente } \\
\text { as respostas } \\
\text { comportamentais } \\
\text { e fisiopatológicas } \\
\text { semelhantes à } \\
\text { depressão. }\end{array}$ & Estresse. & \\
\hline $\begin{array}{l}\text { Buyang Huanwu } \\
\text { Decoction } \\
\text { (补阳还五汤) reduces } \\
\text { infarct volume and } \\
\text { enhances estradiol } \\
\text { and estradiol receptor } \\
\text { concentration in } \\
\text { ovariectomized rats after } \\
\text { middle cerebral artery } \\
\text { occlusion }\end{array}$ & (Liu et al., 2014) & China & \begin{tabular}{|l|} 
Radix Astragali, \\
Astragalus \\
membranaceus, \\
Angelica \\
sinensis, Radix \\
paeoniae \\
rubra, Paeonia \\
lactiflora \\
Pall.; Rhizoma \\
chuanxiong, \\
Ligusticum \\
chuanxiong \\
Hort; \\
Carthamus \\
tinctorius, \\
Semen \\
Persicae, \\
Amygdalus \\
pérsica, \\
Pheretima \\
aspergillum \\
\end{tabular} & \begin{tabular}{|l} 
Experimental. \\
\\
\end{tabular} & $\begin{array}{l}\text { Ratos Wistar } \\
\text { ovariectomizados. }\end{array}$ & 7 dias & $\begin{array}{l}\text { 5g/kg/dia, } \\
\text { decocção }\end{array}$ & $\begin{array}{l}\text { Investigar o efeito } \\
\text { da decocção de } \\
\text { Buyang Huanwu } \\
\text { nos níveis } \\
\text { de estradiol } \\
\text { e receptor } \\
\text { de estradiol } \\
\text { no soro e no } \\
\text { cérebro em ratos } \\
\text { ovariectomizados. }\end{array}$ & $\begin{array}{l}\text { O tratamento melhorou } \\
\text { o comportamento } \\
\text { neurológico, reduziu } \\
\text { o volume do } \\
\text { infarte, aumentou } \\
\text { a concentração de } \\
\text { E2 no soro e no } \\
\text { cérebro, e aumento } \\
\text { da concentração de } \\
\text { receptores de E2 no } \\
\text { cérebro em ratos } \\
\text { ovariectomizados. }\end{array}$ & \begin{tabular}{|l|} 
O tratamento \\
demonstra efeitos \\
neuroprotetores que \\
estão associados \\
ao estrogênio e seu \\
receptor.
\end{tabular} & Neuroproteção & \\
\hline
\end{tabular}


Plantas medicinais utilizadas para o tratamento de distúrbios associados à menopausa

\begin{tabular}{|c|c|c|c|c|c|c|c|c|c|c|c|c|}
\hline Título & Autor & $\begin{array}{l}\text { Local do } \\
\text { estudo }\end{array}$ & Espécie & $\begin{array}{l}\text { Delineamento } \\
\text { experimental }\end{array}$ & $\begin{array}{c}\text { Modelo } \\
\text { experimental }\end{array}$ & $\begin{array}{l}\text { Tempo de } \\
\text { tratamento }\end{array}$ & $\begin{array}{l}\text { Dose e forma de } \\
\text { apresentação do } \\
\text { composto }\end{array}$ & $\begin{array}{l}\text { Objetivo do } \\
\text { trabalho }\end{array}$ & Principais resultados & Conclusão & $\begin{array}{l}\text { Utilização } \\
\text { investigada }\end{array}$ & $\begin{array}{l}\text { Base de } \\
\text { dados }\end{array}$ \\
\hline \multicolumn{13}{|c|}{ Ensaios Experimentais } \\
\hline $\begin{array}{l}\text { Anti-obesity activity of } \\
\text { Yamabushitake (Hericium } \\
\text { erinaceus) powder in } \\
\text { ovariectomized mice, } \\
\text { and its potentially active } \\
\text { compounds }\end{array}$ & (Wang et al., 2016) & Japão & \begin{tabular}{|l|} 
Hericium \\
erinaceus
\end{tabular} & Experimental. & $\begin{array}{l}\text { Camundongos } \\
\text { ovariectomizados. }\end{array}$ & 16 dias & \begin{tabular}{|l|} 
Pó $0,09 \mathrm{~g} /$ \\
dia (média de \\
ingestão/dia) e \\
extrato etanólico \\
$1,87 \pm 0,10 \mathrm{~g} /$ \\
dia, adicionados à \\
dieta.
\end{tabular} & \begin{tabular}{|l|} 
Investigar o efeito \\
antiobesidade de \\
Hericium erinaceus \\
na menopausa.
\end{tabular} & $\begin{array}{l}\text { Aumento dos níveis de } \\
\text { lipídios fecais e inibição } \\
\text { da atividade da lipase. }\end{array}$ & \begin{tabular}{|l|} 
O tratamento \\
apresenta um efeito \\
antiobesidade \\
durante a \\
menopausa, uma \\
vez que diminui \\
a capacidade de \\
absorver lipídios. \\
\end{tabular} & \multirow{3}{*}{$\begin{array}{l}\text { Obesidade e } \\
\text { dislipidemia. }\end{array}$} & \multirow{4}{*}{ Springer } \\
\hline $\begin{array}{l}\text { Inhibitory effects of } \\
\text { Leonurus sibiricus } \\
\text { on weight gain } \\
\text { after menopause in } \\
\text { ovariectomized and high- } \\
\text { fat diet-fed mice }\end{array}$ & (Kim et al., 2016) & $\begin{array}{l}\text { República } \\
\text { da Coreia }\end{array}$ & $\begin{array}{l}\text { Leonurus } \\
\text { sibiricus }\end{array}$ & Experimental. & \begin{tabular}{|l|} 
Camundongos \\
C57BL $/ 6$ \\
ovariectomizadas \\
tratados com dieta \\
hiperlipídica.
\end{tabular} & 6 semanas & $\begin{array}{l}1,10 \text { e } 100 \mathrm{mg} / \mathrm{Kg}, \\
\text { extrato aquoso }\end{array}$ & \begin{tabular}{|l|} 
Verificar os efeitos \\
inibitórios de \\
L.eonurus onurus \\
sibiricus sobre a \\
obesidade após a \\
menopausa.
\end{tabular} & $\begin{array}{l}\text { Redução do peso } \\
\text { corporal total, perfil } \\
\text { lipídico e aumento } \\
\text { da expressão gênica } \\
\text { de lipase triglicerídeo } \\
\text { adiposo e lipase } \\
\text { sensivel a hormônios. }\end{array}$ & $\begin{array}{l}\text { O tratamento } \\
\text { pode regular o } \\
\text { metabolismo } \\
\text { lipídico por meio } \\
\text { do aumento da } \\
\text { expressão de lipases } \\
\text { em camundongos } \\
\text { ovariectomizados. }\end{array}$ & & \\
\hline $\begin{array}{l}\text { Polygonatum } \\
\text { stenophyllum improves } \\
\text { menopausal obesity via } \\
\text { regulation of lipolysis- } \\
\text { related enzymes }\end{array}$ & (Lee et al., 2016) & $\begin{array}{l}\text { República } \\
\text { da Coreia }\end{array}$ & $\begin{array}{l}\text { Polygonatum } \\
\text { stenophyllum }\end{array}$ & Experimental. & \begin{tabular}{|l|} 
Camundongos \\
C57BL/6 \\
ovariectomizados.
\end{tabular} & 6 semanas & $\begin{array}{l}1,10 \text { e } 100 \mathrm{mg} / \\
\mathrm{kg} \text {, extrato aquoso }\end{array}$ & \begin{tabular}{|l|} 
Avaliar os efeitos \\
de extratos \\
aquosos de \\
Polygonatum \\
stenophyllum em \\
camundongos \\
ovariectomizados \\
e alimentados com \\
dieta hiperlipídica.
\end{tabular} & $\begin{array}{l}\text { Redução do peso } \\
\text { corporal, gordura } \\
\text { ovariana e aumento } \\
\text { do peso uterino. } \\
\text { Ainda a administração } \\
\text { do extrato diminuiu } \\
\text { o diâmetro dos } \\
\text { adipócitos e as } \\
\text { gotículas lipídicas } \\
\text { nos hepatócitos com } \\
\text { melhora do perfil } \\
\text { lipídico e aumento da } \\
\text { expressão de genes } \\
\text { relacionados à lipólise. }\end{array}$ & \begin{tabular}{|l|} 
O tratamento \\
pode ter eficácia \\
na obesidade \\
da menopausa, \\
ativando lipase \\
triglicerídeo adiposo \\
e lipase sensível a \\
hormônio.
\end{tabular} & & \\
\hline $\begin{array}{l}\text { Ameliorating effect } \\
\text { of Erxian decoction } \\
\text { combined with Fructus } \\
\text { Schisandrae chinensis } \\
\text { (Wu Wei Zi) on } \\
\text { menopausal sweating } \\
\text { and serum hormone } \\
\text { profiles in a rat model }\end{array}$ & (Wang et al., 2016) & China & $\begin{array}{l}\text { Curculigo } \\
\text { orchioides, } \\
\text { Epimedium } \\
\text { brevicornum, } \\
\text { Melissa } \\
\text { officinalis, } \\
\text { Angelica } \\
\text { sinensis, } \\
\text { Phellodendron } \\
\text { chinense, } \\
\text { Anemarrhena } \\
\text { asphodeloides } \\
\text { e Schisandra } \\
\text { Chinensis }\end{array}$ & Experimental. & $\begin{array}{l}\text { Ratos Sprague- } \\
\text { Dawley com } \\
12 \text { e } 14 \text { meses } \\
\text { de idade com } \\
\text { ciclos irregulares } \\
\text { e baixos níveis } \\
\text { séricos de } \\
\text { estrogênio. }\end{array}$ & 6 semanas & $\begin{array}{l}5.5,11 \text { e } 22 \mathrm{~g} / \mathrm{kg} \text {, } \\
\text { decocção }\end{array}$ & \begin{tabular}{|l|} 
Investigar os \\
efeitos da \\
decoç̧ão na \\
sudorese após \\
menopausa e nos \\
níveis séricos de \\
estrogênio em \\
um modelo de \\
menopausa após a \\
administração oral \\
do tratamento.
\end{tabular} & $\begin{array}{l}\text { Inibição da excreção } \\
\text { de suor e aumento } \\
\text { nos níveis séricos } \\
\text { de estradiol e na } \\
\text { atividade antioxidante. } \\
\text { Além de reduzir } \\
\text { acentuadamente } \\
\text { os níveis séricos do } \\
\text { hormônio folículo- } \\
\text { estimulante, hormônio } \\
\text { luteinizante e } \\
\text { malonaldeído. }\end{array}$ & \begin{tabular}{|l|} 
A decocção inibiu \\
a excreção do \\
suor, regulou os \\
hormônios sexuais e \\
apresentou efeitos \\
antioxidantes. \\
\\
\end{tabular} & $\begin{array}{l}\text { Efeito } \\
\text { Esttogênico }\end{array}$ & \\
\hline
\end{tabular}


Brenda da Silva, Thailene Martins Siochetta, Evelise Moraes Berlezi

\begin{tabular}{|c|c|c|c|c|c|c|c|c|c|c|c|c|}
\hline Título & Autor & $\begin{array}{l}\text { Local do } \\
\text { estudo }\end{array}$ & Espécie & $\begin{array}{l}\text { Delineamento } \\
\text { experimental }\end{array}$ & $\begin{array}{c}\text { Modelo } \\
\text { experimental }\end{array}$ & $\begin{array}{l}\text { Tempo de } \\
\text { tratamento }\end{array}$ & $\begin{array}{l}\text { Dose e forma de } \\
\text { apresentação do } \\
\text { composto }\end{array}$ & $\begin{array}{l}\text { Objetivo do } \\
\text { trabalho }\end{array}$ & Principais resultados & Conclusão & $\begin{array}{l}\text { Utilização } \\
\text { investigada }\end{array}$ & $\begin{array}{l}\text { Base de } \\
\text { dados }\end{array}$ \\
\hline \multicolumn{13}{|c|}{ Ensaios Experimentais } \\
\hline $\begin{array}{l}\text { Estrogenic and cytotoxic } \\
\text { potentials of compounds } \\
\text { isolated from Millettia } \\
\text { macrophylla Benth } \\
\text { (Fabaceae): towards a } \\
\text { better understanding } \\
\text { of its underlying } \\
\text { mechanisms }\end{array}$ & \begin{tabular}{|l} 
(Zingue, Stéphane \\
et al., 2016)
\end{tabular} & Brasil & $\begin{array}{l}\text { Millettia } \\
\text { macrophylla }\end{array}$ & Experimental. & \begin{tabular}{|l} 
Ratas Wistar \\
ovariectomizadas.
\end{tabular} & 3 dias & \begin{tabular}{|l|}
$10 \mathrm{mg} / \mathrm{kg}$, extrato \\
etanólico \\
\\
\\
\end{tabular} & \begin{tabular}{|l|} 
Identificar e isolar \\
os principais \\
compostos \\
presentes \\
em M.illettia \\
macrophylla e \\
avaliar seus efeitos \\
estrogênicos e \\
citotóxicos.
\end{tabular} & $\begin{array}{l}\text { A fração fenólica } \\
\text { atuou de forma mais } \\
\text { eficiente que o extrato } \\
\text { metanólico bruto, } \\
\text { resultando em um } \\
\text { aumento do peso do } \\
\text { útero, nível de proteína } \\
\text { uterina, da altura } \\
\text { epitelial do útero e } \\
\text { da vagina. Além de } \\
\text { redução da duração } \\
\text { média e a frequência } \\
\text { de ondas de calor } \\
\text { induzidas. }\end{array}$ & \begin{tabular}{|l|} 
A fração fenólica de \\
Millettia macrophylla \\
é capaz de aliviar \\
a secura vaginal e \\
ondas de calor em \\
modelo animal de \\
menopausa. \\
\end{tabular} & \multirow{2}{*}{\begin{tabular}{|l} 
Efeito \\
Esttogênico
\end{tabular}} & Springer \\
\hline $\begin{array}{l}\text { Estrogenic effects of } \\
\text { Ficus umbellata Vahl. } \\
\text { (Moraceae) extracts and } \\
\text { their ability to alleviate } \\
\text { some menopausal } \\
\text { symptoms induced by } \\
\text { ovariectomy in Wistar } \\
\text { rats }\end{array}$ & \begin{tabular}{|l|} 
(Zingue, S. et al., \\
2016)
\end{tabular} & Camarões & Ficus umbellata & Experimental. & \begin{tabular}{|l|} 
Ratos Wistar \\
ovariectomizados.
\end{tabular} & 3 dias & \begin{tabular}{|l|}
$50,100,200$ e 300 \\
$\mathrm{mg} / \mathrm{kg}$, extratos \\
metanólico e \\
aquoso
\end{tabular} & \begin{tabular}{|l} 
Investigar as \\
propriedades \\
semelhantes ao \\
estrogênio dos \\
extratos aquoso \\
e metanólico de \\
Ficcus umbellata.
\end{tabular} & \begin{tabular}{|l|} 
Os tratamentos \\
aumentam a espessura \\
do epitélio uterino e \\
vaginal e os níveis de \\
proteína total uterina \\
de maneira dose- \\
dependente, além de \\
reduzir o número total, \\
duração média e a \\
frequência de ondas de \\
calor em animais.
\end{tabular} & \begin{tabular}{|l|} 
Os extratos de Ficcus \\
umbellata têm \\
efeitos semelhantes \\
aos do estrogênio \\
e podem aliviar \\
alguns problemas da \\
menopausa. \\
\end{tabular} & & \multirow[b]{2}{*}{ Science Direct } \\
\hline $\begin{array}{l}\text { A neoflavonoid } \\
\text { dalsissooal isolated from } \\
\text { heartwood of Dalbergia } \\
\text { sissoo Roxb. has bone } \\
\text { forming effects in mice } \\
\text { model for osteoporosis }\end{array}$ & \begin{tabular}{|l|}
$\begin{array}{l}\text { Kushwaha et al., } \\
\text { 2016) }\end{array}$ \\
\end{tabular} & Índia & $\begin{array}{l}\text { Dalbergia } \\
\text { sissoo }\end{array}$ & Experimental. & $\begin{array}{l}\text { Camundongos } \\
\text { Balb, fêmeas } \\
\text { adultas e } \\
\text { osteopênicas. }\end{array}$ & 6 semanas & $\begin{array}{l}1 \text { e } 5 \mathrm{mg} / \mathrm{kg} / \mathrm{dia} \\
\text { por via oral }\end{array}$ & \begin{tabular}{|l|} 
Verificar se \\
o dorsissoal \\
apresenta efeitos \\
antiosteoporóticos \\
em modelos de \\
camundongos \\
para osteoporose. \\
\end{tabular} & $\begin{array}{l}\text { O tratamento possui } \\
\text { ação anabólica } \\
\text { óssea de melhora da } \\
\text { propriedade estrutural } \\
\text { do osso, promovendo } \\
\text { nova formação } \\
\text { óssea e reduzindo a } \\
\text { taxa de renovação } \\
\text { óssea no modelo } \\
\text { pós-menopausa para } \\
\text { osteoporose, sem } \\
\text { hiperplasia uterina. }\end{array}$ & $\begin{array}{l}\text { O tratamento } \\
\text { apresenta efeitos } \\
\text { benéficos na } \\
\text { prevenção da } \\
\text { perda óssea no } \\
\text { modelo animal de } \\
\text { osteoporose pós- } \\
\text { menopausa. }\end{array}$ & Osteoporose & \\
\hline
\end{tabular}


Plantas medicinais utilizadas para o tratamento de distúrbios associados à menopausa

\begin{tabular}{|c|c|c|c|c|c|c|c|c|c|c|c|c|}
\hline Título & Autor & $\begin{array}{l}\text { Local do } \\
\text { estudo }\end{array}$ & Espécie & $\begin{array}{l}\text { Delineamento } \\
\text { experimental }\end{array}$ & $\begin{array}{c}\text { Modelo } \\
\text { experimental }\end{array}$ & $\begin{array}{l}\text { Tempo de } \\
\text { tratamento }\end{array}$ & $\begin{array}{l}\text { Dose e forma de } \\
\text { apresentação do } \\
\text { composto }\end{array}$ & $\begin{array}{c}\text { Objetivo do } \\
\text { trabalho }\end{array}$ & Principais resultados & Conclusão & $\begin{array}{c}\text { Utilização } \\
\text { investigada }\end{array}$ & $\begin{array}{l}\text { Base de } \\
\text { dados }\end{array}$ \\
\hline \multicolumn{13}{|c|}{ Ensaios Experimentais } \\
\hline $\begin{array}{l}\text { A Root-Based } \\
\text { Combination Supplement } \\
\text { Containing Pueraria } \\
\text { lobata and Rehmannia } \\
\text { glutinosa and Exercise } \\
\text { Preserve Bone Mass in } \\
\text { Ovariectomized Rats Fed } \\
\text { a High-Fat Diet }\end{array}$ & (Ok et al., 2015) & $\begin{array}{l}\text { República } \\
\text { da Coreia }\end{array}$ & $\begin{array}{l}\text { Pueraria } \\
\text { montana e } \\
\text { Rehmannia } \\
\text { glutinosa }\end{array}$ & Experimental. & \begin{tabular}{|l|} 
Ratos Sprague- \\
Dawley \\
ovariectomizados, \\
tratados com dieta \\
hiperlipídica.
\end{tabular} & 8 semanas & $\begin{array}{l}400 \mathrm{mg} / \mathrm{kg} \text {, } \\
\text { extrato combinado } \\
\text { das plantas por } \\
\text { via oral }\end{array}$ & $\begin{array}{l}\text { Avaliar os efeitos } \\
\text { de um suplemento } \\
\text { contendo extrato } \\
\text { de raiz de Pueraria } \\
\text { lobata/Rehmannia } \\
\text { glutinosa } \\
\text { no turnover } \\
\text { ósseo em ratos } \\
\text { ovariectomizados } \\
\text { (OVX). }\end{array}$ & $\begin{array}{l}\text { O tratamento } \\
\text { aumentou a taxa de } \\
\text { renovação óssea e } \\
\text { induziu modificações } \\
\text { arquitetônicas } \\
\text { favoráveis do osso } \\
\text { trabecular. Além disso, } \\
\text { o tratamento reduziu } \\
\text { a atividade da cascata } \\
\text { de sinalização de } \\
\text { proteínas envolvidas } \\
\text { na regeneração e } \\
\text { remodelação óssea. }\end{array}$ & $\begin{array}{l}\text { O tratamento foi } \\
\text { capaz de melhorar } \\
\text { a microarquitetura } \\
\text { cortical do fêmur } \\
\text { e diminuir os } \\
\text { marcadores de } \\
\text { renovação óssea e } \\
\text { expressão de genes } \\
\text { osteoclastogênicos } \\
\text { esqueléticos no } \\
\text { fêmur. }\end{array}$ & \multirow{4}{*}{ Osteoporose } & \multirow[t]{2}{*}{ Springer } \\
\hline $\begin{array}{l}\text { Antiosteoporotic effects } \\
\text { of Pueraria candollei } \\
\text { var. mirifica on bone } \\
\text { mineral density and } \\
\text { histomorphometry in } \\
\text { estrogen-deficient rats }\end{array}$ & $\begin{array}{l}\text { (Suthon et al., } \\
\text { 2016) }\end{array}$ & Tailândia & $\begin{array}{l}\text { Pueraria } \\
\text { mirifica. }\end{array}$ & Experimental. & $\begin{array}{l}\text { Ratas } \\
\text { ovariectomizadas. }\end{array}$ & 12 Semanas & $\begin{array}{l}0.5,25 \text { e } 50 \mathrm{mg} / \\
\mathrm{kg} / \mathrm{dia} \text {, suspensão } \\
\text { em pó }\end{array}$ & $\begin{array}{l}\text { Determinar se } \\
\text { Pueraria candollei } \\
\text { var. mirifica e } \\
\text { puerarina podem } \\
\text { exercer efeitos } \\
\text { antiosteoporóticos } \\
\text { em ratos } \\
\text { osteoporóticos } \\
\text { induzidos por } \\
\text { ovariectomia. }\end{array}$ & \begin{tabular}{|l} 
As densidades minerais \\
ósseas trabeculares \\
da metáfise da tíbia \\
e DMOs totais e \\
trabeculares da L4 do \\
grupo tratado com \\
$50 \mathrm{mg} / \mathrm{kg}$ foi maior \\
do que as do grupo \\
tratado com $0.5 \mathrm{mg} / \mathrm{kg}$. \\
\end{tabular} & $\begin{array}{l}\text { O tratamento } \\
\text { pode reter, } \\
\text { principalmente, a } \\
\text { massa óssea nos } \\
\text { níveis anteriores } \\
\text { à perda óssea, } \\
\text { ainda, a planta } \\
\text { pode ser usada } \\
\text { como um agente } \\
\text { antiosteoporótico } \\
\text { para mulheres na } \\
\text { pós-menopausa. }\end{array}$ & & \\
\hline $\begin{array}{l}\text { Cissus } \\
\text { quadrangularis prevented } \\
\text { the ovariectomy induced } \\
\text { oxidative stress in the } \\
\text { femur of adult albino rats }\end{array}$ & $\begin{array}{l}\text { (Muthusami et al., } \\
\text { 2016) }\end{array}$ & Índia & \begin{tabular}{|l|} 
Cissus \\
quadrangularis
\end{tabular} & Experimental. & \begin{tabular}{|l|} 
Ratos wistar \\
ovariectomizadas.
\end{tabular} & 15 semanas & $\begin{array}{l}100 \text { e } 250 \mathrm{mg} / \mathrm{kg} \text {, } \\
\text { extrato etanólico }\end{array}$ & \begin{tabular}{|l} 
Verificar o \\
efeito de Cissus \\
quadrangularis \\
sobre o sistema \\
antioxidante do \\
fêmur em ratas \\
ovariectomizadas. \\
\end{tabular} & \begin{tabular}{|l|} 
A administração do \\
tratamento manteve \\
as atividades \\
enzimáticas preservadas \\
em ratas \\
ovariectomizadas.
\end{tabular} & $\begin{array}{l}\text { O extrato etanólico } \\
\text { de } C \text {. quadrangularis } \\
\text { previne o estresse } \\
\text { oxidativo no fêmur } \\
\text { induzido pela } \\
\text { ovariectomia. }\end{array}$ & & ScienceDirect \\
\hline $\begin{array}{l}\text { Effects of Artemisia } \\
\text { princeps supplementation } \\
\text { on bone metabolism in } \\
\text { ovariectomized rats }\end{array}$ & (Cho et al., 2016) & Coreia. & \begin{tabular}{|l} 
Artemisia \\
princeps
\end{tabular} & Experimental. & \begin{tabular}{|l} 
Ratas Sprague- \\
Dawley \\
ovariectomizadas.
\end{tabular} & 15 semanas & $\begin{array}{l}100 \text { e } 300 \mathrm{mg} / \\
\mathrm{kg} / \text { dia, extrato } \\
\text { etanólico }\end{array}$ & $\begin{array}{l}\text { Investigar os } \\
\text { efeitos da } \\
\text { Artemisia princeps } \\
\text { (AP) extrato do } \\
\text { metabolismo } \\
\text { ósseo e seu } \\
\text { papel potencial } \\
\text { na prevenção } \\
\text { da osteoporose } \\
\text { em ratas } \\
\text { ovariectomizadas. }\end{array}$ & $\begin{array}{l}\text { Prevenção da redução } \\
\text { da espessura óssea e } \\
\text { da densidade mineral } \\
\text { óssea trabecular } \\
\text { causada pela excreção } \\
\text { urinária de cálcio } \\
\text { e cromo, além de } \\
\text { prevenir o aumento } \\
\text { do turnover ósseo, } \\
\text { melhorando assim a } \\
\text { microarquitetura do } \\
\text { osso trabecular e do } \\
\text { osso cortical após a } \\
\text { ovariectomia. }\end{array}$ & $\begin{array}{l}\text { O tratamento } \\
\text { preveniu a perda } \\
\text { óssea e a atividade } \\
\text { dos osteoclastos } \\
\text { associada à alta } \\
\text { remodelação } \\
\text { óssea em ratas } \\
\text { ovariectomizada, } \\
\text { controlando a } \\
\text { relação sérica de } \\
\text { Ca/P e por meio } \\
\text { de propriedades } \\
\text { anti-inflamatórias e } \\
\text { antioxidantes. }\end{array}$ & & Springer \\
\hline
\end{tabular}


Brenda da Silva, Thailene Martins Siochetta, Evelise Moraes Berlezi

\begin{tabular}{|c|c|c|c|c|c|c|c|c|c|c|c|c|}
\hline $\begin{array}{l}\text { Ethanolic extract of } \\
\text { Coelogyne cristata } \\
\text { Lindley (Orchidaceae) and } \\
\text { its compound coelogin } \\
\text { promote osteoprotective } \\
\text { activity in ovariectomized } \\
\text { estrogen deficient mice }\end{array}$ & $\begin{array}{l}\text { (Sharma et al., } \\
\text { 2014) }\end{array}$ & Índia & $\begin{array}{l}\text { Coelogyne } \\
\text { cristata }\end{array}$ & Experimental. & \begin{tabular}{|l} 
Camundongos \\
Balb \\
ovariectomizados
\end{tabular} & 4 semanas. & $\begin{array}{l}5,10 \text { e } 20 \mathrm{mg} / \mathrm{kg} \\
\text { extrato etanólico }\end{array}$ & $\begin{array}{l}\text { Avaliado a } \\
\text { atividade de } \\
\text { formação óssea, } \\
\text { microarquitetura } \\
\text { trabecular, } \\
\text { resistência óssea } \\
\text { e estrogenicidade } \\
\text { uterina. }\end{array}$ & $\begin{array}{l}\text { O tratamento } \\
\text { promoveu a } \\
\text { restauração da } \\
\text { microestrutura } \\
\text { trabecular nos ossos } \\
\text { femoral e tibial, } \\
\text { melhorou a qualidade } \\
\text { óssea e também } \\
\text { demonstrou ser } \\
\text { desprovido de qualquer } \\
\text { estrogenicidade uterina } \\
\text { no modelo animal } \\
\text { estudado. }\end{array}$ & $\begin{array}{l}\text { O extrato } \\
\text { apresentou efeitos } \\
\text { osteoprotetores } \\
\text { e demonstrou } \\
\text { ser desprovido } \\
\text { de qualquer } \\
\text { estrogenicidade } \\
\text { uterina em qualquer } \\
\text { das doses. }\end{array}$ & \multirow{3}{*}{ Osteoporose } & $\begin{array}{l}\text { Science } \\
\text { Direct }\end{array}$ \\
\hline $\begin{array}{l}\text { Preventive effects of } \\
\text { withaferin A isolated } \\
\text { from the leaves of an } \\
\text { Indian medicinal plant } \\
\text { Withania somnifera } \\
\text { (L.): Comparisons with } \\
\text { 17- } \beta \text {-estradiol and } \\
\text { alendronate. }\end{array}$ & $\begin{array}{l}\text { (Khedgikar et al., } \\
\text { 2015) }\end{array}$ & Índia & $\begin{array}{l}\text { Withania } \\
\text { somnifera }\end{array}$ & Experimental. & \begin{tabular}{|l|} 
Camundongos \\
Balb \\
ovariectomizados.
\end{tabular} & 8 semanas & $\begin{array}{l}1,5,10 \mathrm{mg} / \mathrm{kg} \text { por } \\
\text { via oral }\end{array}$ & $\begin{array}{l}\text { Avaliar os efeitos } \\
\text { protetores ósseos } \\
\text { de withaferina A } \\
\text { (WFA) de folhas } \\
\text { de Withania } \\
\text { somnifera (L.) } \\
\text { em modelo de } \\
\text { menopausa com } \\
\text { 17ß-estradiol (E2) } \\
\text { e alendronato } \\
\text { (ALD). }\end{array}$ & $\begin{array}{l}\text { A administração de } \\
\text { WFA aumentou a } \\
\text { neoformação óssea, } \\
\text { além de melhorar a } \\
\text { microarquitetura e a } \\
\text { força biomecânica dos } \\
\text { ossos. Evitou a perda } \\
\text { óssea reduzindo a } \\
\text { expressão dos genes } \\
\text { osteoclásticos fosfatase } \\
\text { ácida resistente ao } \\
\text { tartarato e ativador } \\
\text { do receptor do fator } \\
\text { nuclear k B. }\end{array}$ & $\begin{array}{l}\text { A WFA tem } \\
\text { potencial protetor } \\
\text { ósseo, pois seu } \\
\text { tratamento previne } \\
\text { a perda óssea que } \\
\text { é comparável à ALD } \\
\text { e E2. } \\
\end{array}$ & & Ebesco \\
\hline $\begin{array}{l}\text { Time and dose- } \\
\text { dependent effects } \\
\text { of Labisia pumila on } \\
\text { the bone strength } \\
\text { of postmenopausal } \\
\text { osteoporosis rat model }\end{array}$ & \begin{tabular}{|l} 
(Mohd Effendy et \\
al., 2015)
\end{tabular} & Malásia & Labisia pumila & Experimental. & \begin{tabular}{|l} 
Ratos Sprague- \\
Dawley \\
Ovariectomia
\end{tabular} & 9 semanas & $\begin{array}{l}20 \text { e } 100 \mathrm{mg} / \\
\mathrm{kg} \text {, extrato seco } \\
\text { dissolvido em } \\
\text { água }\end{array}$ & \begin{tabular}{|l|} 
Determinar \\
os efeitos da \\
suplementação \\
com Labisia \\
pumila na força \\
biomecânica óssea \\
em modelo animal \\
de menopausa e \\
osteoporose. \\
\end{tabular} & $\begin{array}{l}\text { Os animais } \\
\text { suplementados } \\
\text { apresentaram } \\
\text { melhorias nos } \\
\text { parâmetros de } \\
\text { resistência óssea, } \\
\text { como carga máxima, } \\
\text { deslocamento, rigidez, } \\
\text { estresse e Young } \\
\text { Modulus. }\end{array}$ & \begin{tabular}{|l|} 
A suplementação \\
de L. pumila var. \\
alata a $100 \mathrm{mg} /$ \\
kg foi mais efetiva \\
que a terapia de \\
reposição hormonal \\
na reversão \\
das alterações \\
biomecânicas ósseas \\
induzidas pela \\
ovariectomia. \\
\end{tabular} & & Springer \\
\hline $\begin{array}{l}\text { The Natural Substance } \\
\text { MS-10 Improves and } \\
\text { Prevents Menopausal } \\
\text { Symptoms, Including } \\
\text { Colpoxerosis, in Clinical } \\
\text { Research. }\end{array}$ & (Noh et al., 2016) & Coreia. & \begin{tabular}{|l} 
Cirsium \\
japonicum \\
e Thymus \\
vulgaris
\end{tabular} & Experimental. & \begin{tabular}{|l|} 
Ratos Sprague \\
Dawley \\
ovariectomizados.
\end{tabular} & 8 semanas & $\begin{array}{l}50 \mathrm{mg} / \mathrm{kg} \text {, extrato } \\
\text { alcóolico seco }\end{array}$ & $\begin{array}{l}\text { Examinar o efeito } \\
\text { do composto MS- } \\
10 \text { contendo as } \\
\text { plantas medicinais } \\
\text { sobre a melhora } \\
\text { e prevenção do } \\
\text { ganho de peso, } \\
\text { anormalidades } \\
\text { no metabolismo } \\
\text { liṕ́dico e perda } \\
\text { óssea em ratos } \\
\text { ovariectomizados } \\
\text { como modelo } \\
\text { pré-clínico da } \\
\text { menopausa. }\end{array}$ & $\begin{array}{l}\text { O tratamento } \\
\text { apresentou efeitos } \\
\text { benéficos em células } \\
\text { que expressam o } \\
\text { receptor de estrogênio, } \\
\text { aumentando } \\
\text { reversivelmente a } \\
\text { atividade estrogênica. } \\
\text { Além disso, no } \\
\text { modelo de estudo, as } \\
\text { alterações na atividade } \\
\text { da fosfatase alcalina } \\
\text { específica óssea e } \\
\text { osteocalcina, foi } \\
\text { verificado uma melhora } \\
\text { dos níveis lipídicos. } \\
\end{array}$ & $\begin{array}{l}\text { O tratamento é } \\
\text { capaz de proteger } \\
\text { a saúde óssea e } \\
\text { reduzir distúrbios } \\
\text { metabólicos. } \\
\\
\end{array}$ & $\begin{array}{l}\text { Osteoporose e } \\
\text { dislipidemias }\end{array}$ & Pubmed \\
\hline
\end{tabular}




\section{DISCUSSÃO}

As evidências dos artigos selecionados trazem uma gama de plantas medicinais com potencial para o tratamento dos mais diversos sintomas e patologias associados à menopausa, demonstrando que os fitogêneos podem ser uma alternativa bastante efetiva, de baixo custo e com pouca ou nenhuma apresentação de efeitos adversos, como observado na TRH.

Por questões estruturais esta sessão foi dividida em duas grandes subseções: Doenças Associadas à Menopausa e Sintomas Associados à Menopausa, que serão subdivididas de acordo com a característica potencial das plantas investigadas pelos autores dos estudos selecionados.

\section{DOENÇAS ASSOCIADAS À MENOPAUSA}

Em geral, mulheres têm uma esperança de vida mais longa em relação aos homens, contudo, em razão do maior tempo de exposição aos fatores de risco para doenças crônicas durante a vida, estas possuem um risco elevado quando comparadas aos homens para o desenvolvimento de doenças crônicas relacionadas à idade. Entre as principais doenças que acometem mulheres idosas, destacam-se as cardiovasculares e as cerebrovasculares ${ }^{9}$.

Com a menopausa e a deficiência de E2 acontece uma série de alterações cardiometabólicas no organismo feminino, que podem acometer a mulher geralmente na sexta década de vida, e estas incluem obesidade, disfunção metabólica, doenças cardiovasculares, osteoporose, artrite, demência, declínio da cognição e câncer ${ }^{10}$. A partir disto, esta sessão está estruturada para esclarecer as plantas medicinais investigadas no tratamento de diversas patologias, entre elas: osteoporose, doenças cardiovasculares e, pelo seu potencial, efeito neuroprotetor.

\section{Osteoporose}

A osteoporose é uma doença que acomete mulheres na pós-menopausa e é caracterizada pela redução da massa e deterioração da microarquitetura óssea, frequentemente associada à privação de E2. À medida que a idade avança, a gravidade desta doença aumenta e, consequentemente, a morbimortalidade associada a ela. Em pequenas doses o E2 é capaz de prevenir a perda óssea esquelética dificultando a reabsorção óssea mediada por osteoclastos $^{11-13}$.

Os fitoestrógenos vêm sendo estudados como uma terapia alternativa, uma vez que possuem estruturas semelhantes ao E2. Diversos autores têm evidenciado os efeitos protetores dos fitoestrógenos na manutenção da massa óssea durante a menopausa. Eles atuam em diferentes vias e promovem a resposta anabólica óssea estimulando a capacidade das células formadoras de osso em aumentar a proliferação e diferenciação do osteoblastos ${ }^{11-16}$. Neste sentido, os estudos abordados nessa sessão envolvem plantas medicinais que possuem potencial efeito no tratamento da osteoporose pós-menopáusica.

Neste sentido, Kushwaha et al. ${ }^{14}$ demonstraram, em um modelo animal de menopausa e osteoporose, que o Dorsissoal, um flavonoide extraído do cerne de Dalbergia sissoo, é capaz de melhorar a microarquitetura, qualidade e resistência óssea, além de reduzir a reabsorção óssea. Estes efeitos benéficos na prevenção da perda óssea no modelo de ratos com osteoporose pós-menopausa, foram comparáveis com os efeitos demonstrados pelo E2, sem promover efeitos adversos endometriais ${ }^{14}$. Já Ok et al. ${ }^{7}$ investigaram um suplemento contendo Pueraria lobata e Rehmannia associado ao exercício aeróbico no tratamento da osteoporose pós-menopáusica em camundongos ovariectomizados, quando evidenciaram que o tratamento com o composto, durante oito semanas, e/ou exercício aeróbico, melhoraram a microarquitetura cortical do fêmur e reduziram os marcadores de renovação óssea e expressão de genes osteoclastogênicos esqueléticos no fêmur?.

Outro estudo envolvendo a Artemisia princeps, uma planta tradicional encontrada na Coreia, descreve seu efeito sobre a prevenção da redução da espessura óssea e da densidade mineral óssea trabecular causada pela excreção urinária de Cálcio e Cromo, além de prevenir o aumento do turnover ósseo pela manutenção da relação Cálcio/ Potássio sérica. Houve melhora da microarquitetura do osso trabecular e do osso cortical após a ovariectomia em um modelo animal ${ }^{17}$. Neste mesmo sentido, Muthusami et $a l .^{18}$ verificaram os efeitos da administração do extrato etanólico de Cissus quadrangularis em um modelo animal de menopausa e evidenciaram que o tratamento demonstra uma atividade protetora do sistema antioxidante ósseo ${ }^{18}$, enquanto o tratamento durante 12 semanas com Pueraria mirifica foi capaz de recuperar a massa óssea perdida ao longo da menopausa. Além disto, a planta pode ser usada como um agente antiosteoporótico para mulheres na pós-menopausa ${ }^{16}$.

Enquanto Mohd Effendy et al. ${ }^{15}$ evidenciaram que a suplementação com Labisia pumila, em animais após ovariectomia, promove melhorias nos parâmetros de resistência óssea, tais como carga máxima, deslocamento, rigidez e estresse oxidativo ósseo ${ }^{15}$, outro estudo, conduzido na Índia, avaliou os efeitos de proteção óssea da Withaferina A (WFA) extraída das folhas de Withania somnifera em modelo de menopausa comparando-se o tratamento com E2 e alendronato, evidenciando que a administração de WFA promove aumento da neoformação óssea, além de evitar a perda de massa, melhorar a microarquitetura e a força biomecânica dos ossos. Além disso, verificou-se a redução do marcador de turnover ósseo, osteocalcina e fator de necrose tumoral de citocinas inflamatórias induzido pela ovariectomia, apresentando, então, efeitos comparáveis à administração de E2. Ainda, a nível celular, a WFA promoveu a diferenciação de células da medula óssea e aumentou a mineralização, induzindo à expressão de genes osteogênicos ${ }^{19}$. 


\section{Doenças Cardiovasculares}

As doenças cardiovasculares estão entre as principais causas de mortes em mulheres no mundo desenvolvido ${ }^{10}$. Estudos epidemiológicos demonstram que as mulheres possuem certo nível de proteção em se tratando de doenças coronárias antes da menopausa, sugerindo uma ação benéfica do $E 2^{20}$, posto que, na pré-menopausa, as concentrações de colesterol total (CT) e lipoproteínas de baixa densidade (LDL) são menores, enquanto as lipoproteínas de alta densidade (HDL) estão elevadas. A redução da disponibilidade de E2 na circulação exerce efeitos nocivos ao metabolismo lipídico e aumento do risco de doença cardiovascular $^{21}$, uma vez que, após a menopausa, as mulheres perdem esse perfil lipídico benéfico, passando a apresentar elevação de CT, LDL e subsequente redução de $\mathrm{HDL}^{20}$. Neste sentido, esta sessão apresentará plantas que vêm sendo estudadas para tratamento da dislipidemia e alterações metabólicas associadas à menopausa e que podem incrementar o risco de desenvolvimento de doenças cardiovasculares.

Zhang et al. ${ }^{22}$ investigaram duas fórmulas contendo plantas da medicina tradicional chinesa. Um composto contendo Eucommia ulmoides, Psoraleae fructus e Salvia miltiorrhiza, quando se evidenciou a capacidade das plantas em exercer efeitos estrogênicos na melhoria da estrutura de órgãos-alvo, tais como útero e ossos, além de atuar na modulação do metabolismo endócrino. Ainda, os tratamentos apresentaram capacidade de atuar na redução de colesterol LDL e triglicerídeos por meio da ativação de receptores de E2 ${ }^{22}$. Neste mesmo sentido, os extratos aquosos de Leonurus sibiricus e Polygonatum stenophyllum também desempenharam um papel importante na redução de peso corporal total, tamanho dos adipócitos e peso da gordura visceral e da infiltração de gordura do fígado. Foram observadas, ainda, reduções nos níveis séricos de triglicérides, CT, LDL e aumento da expressão de genes relacionados à lipólise, incluindo lipase triglicerídeo adiposo e lipase sensível a hormônios. Ainda, Polygonatum stenophyllum demonstra capacidade de aumentar o peso uterino e reduzir a gordura ovariana em um modelo animal de menopausa ${ }^{23,24}$.

Outro estudo, realizado na Malásia com mulheres menopausadas, evidenciou que o pó da semente de Nigella sativa, administrado na dose de $1 \mathrm{~g} /$ dia durante oito semanas, é capaz de promover um efeito hipolipemiante de redução de CT, LDL e TG, além de aumentar os níveis de HDL. Os autores ainda demonstraram que a planta pode reduzir a glicemia e a pressão arterial em mulheres menopausadas ${ }^{25}$. Por outro lado, Hiraki et al. (2017) investigaram o uso do pó e o extrato de Hericium erinaceus em camundongos ovariectomizados durante 16 dias, e demonstraram que a planta possui efeito antiobesidade quando administrada durante a menopausa, uma vez que reduz a capacidade de absorção de lipídios provenientes da dieta ${ }^{26}$.

Já o extrato aquoso da combinação de três plantas medicinais - Artemisia princeps, Leonurus japonicas e Gardenia jasminoides -, administrado por um período de oito semanas, é capaz de melhorar a dislipidemia e a intolerância à glicose, além de inibir o gasto energético, a oxidação dos ácidos graxos, a resistência à insulina, potencializar a expressão do ativador de proliferação de peroxissoma 1-alfa no fígado e melhorar a tolerância à glicose em um modelo animal de menopausa. Ainda, os extratos foram capazes de inibir a gliconeogênese no estado alimentado pela supressão da expressão da fosfoenolpiruvato carboxiquinase, demonstrando seu potente efeito no metabolismo e balanço energético no mesmo modelo animal ${ }^{27}$. Neste mesmo sentido, a Olea europaea vem sendo bastante utilizada na medicina tradicional para o tratamento de diversas afecções à saúde, e, em um estudo realizado na Espanha, verificou-se que o extrato das folhas desta planta é um potente antioxidante capaz de reduzir principalmente a peroxidação lipídica em mulheres na pós-menopausa ${ }^{28}$.

\section{Efeito neuroprotetor}

O E2 possui uma ampla variedade de funções em âmbito de sistema nervoso central, especialmente na cognição, aprendizagem e memória, além de desempenhar um papel protetor contra a oxidação e condições degenerativas mediadas pelo estresse oxidativo cerebral. A cessação da produção de E2 pela falência ovariana decorrente da menopausa, portanto, é conhecida por aumentar a incidência de patologias inflamatórias envolvendo estresse oxidativo, além de ser um fator de risco para doenças neurodegenerativas, como o Alzheimer ${ }^{29}$. Estudos vêm demonstrando que a TRH, ou terapia com suplemento de fitoestrógenos, exerce efeitos preventivos na mediação do estresse oxidativo e distúrbios neurodegenerativos ${ }^{30}$. A partir disto, esta sessão apresenta o compilado dos achados em estudos envolvendo plantas medicinais para neuroproteção na condição de menopausa.

Buyang Huanwu, uma planta tradicional chinesa, foi estudada quanto aos seus efeitos neuroprotetores em um modelo animal de menopausa, e verificou-se que o tratamento durante sete dias com a decocção da planta meIhorou significativamente o comportamento neurológico, reduziu o volume do enfarte, aumentou a concentração de E2 no soro e no cérebro, além de promover aumento de receptores de E2 cerebrais em ratos ovariectomizados após oclusão da artéria cerebral média ${ }^{31}$.

Por outro lado, o Miroesterol, composto isolado da Pueraria candollei, também demonstrou capacidade de atenuar a disfunção cognitiva induzida pela ovariectomia em um modelo animal, além de reverter significativamente essas alterações neuroquímicas causadas pelo procedimento $^{32}$. O mesmo composto foi descrito por promover ação antioxidante por intermédio da melhora do sistema antioxidante enzimático no fígado e útero de camundongos normais e tratados com $\beta$-naftoflavona $(B N F)$, uma biomolécula que está envolvida na carci- 
nogênese. Verificou-se que o tratamento aumentou a atividade de enzimas do sistema antioxidante como superóxido dismutase no útero de camundongos normais, e catalase no fígado de ambos e camundongos tratados com BNF. No fígado, o Miroesterol aumentou os níveis de diversas isoformas de glutationa, enquanto no útero o E2 e o Miroesterol reduziram o nível de peroxidação lipídica demonstrado pela redução dos níveis séricos de malondialdeído ${ }^{33}$.

O Soyo-san é uma fórmula medicinal oriental tradicional que contém o extrato bruto de uma série de plantas medicinais, sendo elas: Paeoliae radix alba, Atractylodis Macrocephalae phizoma, Angelicae gigantis radix, Poria, Liriopis tuber, Bupleuri radix, Menthae herba, Glycyrrhizae radix e Zingiberi rhizoma recens. Park et al. (2014) buscaram investigar se a administração de Soya-san foi capaz de modular o comportamento depressivo e a produção de citocinas pró-inflamatórias em um modelo animal de menopausa. Durante o teste de nado forçado, os animais tratados apresentaram mais mobilidade em relação aos não tratados, além de um aumento no tempo de nado. Ademais disso, houve redução dos níveis séricos de corticosterona e interleucina (IL)-1ß e aumento da expressão de neurônios positivos para IL-1 $\beta$ no cérebro e no núcleo paraventricular cerebral ${ }^{34}$.

\section{SINTOMAS ASSOCIADOS À MENOPAUSA}

Dentre as principais alterações funcionais que ocorrem durante a menopausa tem-se a atrofia uterina, secura vaginal, dispareunia, distúrbios menstruais, redução da libido e da calcificação dos ossos, ansiedade, depressão, irritabilidade, redução do tamanho das mamas, incontinência urinária, ondas de calor ou fogachos, caracterizados pelo enrubescimento da pele e alterações vasculares, distúrbios do sono e fadiga. Para tanto, a busca por tratamentos alternativos e complementares que proporcionem uma melhora parcial ou completa das alterações decorrentes da menopausa tornam-se fundamentais, especialmente aquelas provenientes de produtos naturais com ação anti-inflamatória, antiaterosclerótica e antioxidante, tendo em vista que os tratamentos de reposição hormonal ainda apresentam risco e efeitos adversos $^{6}$. Neste sentido, nesta sessão estão agrupadas as plantas investigadas para o tratamento dos sintomas associados à menopausa.

\section{Ondas de Calor}

As ondas de calor são sensações intensas de calor que ocorrem principalmente no tórax e no rosto e afetam a grande maioria das mulheres na meia-idade ou após te- rapias de inibição de E2 e/ou ooforectomia. Clinicamente, a sensação subjetiva de calorões correlaciona-se bem com aumentos de vasodilatação cutânea mediados pelo sistema nervoso simpático que acumulam sangue a 37 ำ na pele. Isso, por sua vez, interage com sensores térmicos periféricos na pele para sinalizar o calor e promover sudorese intensa ${ }^{35,36}$.

Em um estudo realizado na China, utilizando a decocção de plantas medicinais tradicionalmente empregadas para o tratamento de sintomas associados à menopausa, sendo estas Curculigo orchioides, Epimedium brevicornum, Melissa officinalis, Angelica sinensis, Phellodendron chinense, Anemarrhena asphodeloides e Schisandrae Chinensis, foi verificado que o tratamento durante seis semanas é capaz de inibir significativamente a excreção de suor em um modelo animal de menopausa. Além disto, a decocção destas plantas reduziu acentuadamente o número de células secretoras nas glândulas sudoríparas plantares, aumentou os níveis séricos de E2, as atividades de superóxido dismutase e reduziu acentuadamente os níveis séricos do hormônio folículo-estimulante, hormônio luteinizante e da peroxidação lipídica ${ }^{37}$. Outro estudo verificou a eficácia e segurança do estigma de Crocus sativus (açafrão) no tratamento do transtorno depressivo maior, associado a ondas de calor na pós-menopausa, e demonstrou que o tratamento durante seis semanas com a planta é capaz de reduzir significativamente os calorões e alguns escores de depressão ${ }^{38}$.

Outra planta que vem sendo utilizada na medicina tradicional para tratamento dos sintomas associados à menopausa é a Millettia macrophylla. Em um estudo que envolveu a administração durante três dias do extrato metanólico e da fração fenólica da planta na dose de $10 \mathrm{mg} / \mathrm{Kg}$ em um modelo animal de menopausa, foi evidenciado que a fração fenólica possui maior atividade sobre o peso do útero, nível de proteína uterina, altura da camada epitelial uterina e da vagina, além de reduzir a duração média e a frequência de ondas de calor induzidas pela ovariectomia nos animais ${ }^{39}$.

\section{Alterações Sexuais}

Entre os principais sintomas associados à menopausa, a atrofia vaginal é uma condição comum que ocorre entre mulheres pós-menopáusicas em razão da depleção dos níveis de E2. Os sinais e sintomas da atrofia vaginal incluem epitélio pálido, secura dos lábios da vagina, inflamação, petéquias e aumento da friabilidade do tecido, o que acomete diretamente a qualidade de vida destas mulheres ${ }^{40}$.

Em um estudo desenvolvido no Irã, o uso do creme vaginal de Pimpinella anisum em mulheres menopausadas com disfunção sexual foi capaz de apresentar uma melhora significativa em todas as áreas da função sexual, incluindo excitação, lubrificação, orgasmo, satisfação sexual e dor, além do escore total do Índice de Função Sexual Feminina após oito semanas de tratamento ${ }^{41}$.

A Foeniculum vulgare, planta cuja fruta possui grande quantidade de fitoestrógenos, é bastante estudada por

seu efeito em aumentar o leite materno, melhorar os sintomas pré-menstruais, aumentar a libido e melhorar os 
sintomas da menopausa em mulheres na pós-menopausa. Em estudos desenvolvidos no Irã ficou evidente que o tratamento com creme vaginal da planta induz o aumento do número de células superficiais, reduz o $\mathrm{pH}$, número de células intermediárias e parabasais do epitélio vaginal ${ }^{42}$, enquanto o tratamento via oral, com o extrato etanólico da planta, promove melhora da gravidade média dos sintomas associados à menopausa ${ }^{43}$.

Neste mesmo sentido, a Ficus umbellata vem sendo estudada em virtude de seus efeitos semelhantes ao E2; contudo em dois estudos desenvolvidos na França foi evidenciado que os extratos metanólico e aquoso da planta apresentam atividade semelhante ao E2 e podem aliviar alguns sinais e sintomas associados à menopausa, tais como secura vaginal e calorões ${ }^{44}$. Os autores ainda estudaram os efeitos da 7-metoxicumarina, um dos compostos majoritários, isolado do extrato metanólico de Ficus umbellata, e verificaram que o componente possui uma fraca atividade estrogênica in vitro e in vivo, o que explica apenas parcialmente o efeito estrogênico do extrato da planta inteira. O composto isolado da planta, 7-metoxicumarin, pode ser benéfico no que diz respeito à secura da vagina, uma vez que mostra um efeito específico do tecido sem expor o útero a um potencial crescimento tumorigênico ${ }^{45}$.

\section{CONCLUSÃO}

As plantas medicinais examinadas pelos estudos selecionados apresentaram efeitos relevantes sobre os sintomas fisiopatológicos associados à menopausa atuando em diferentes mecanismos de ação. A partir do exposto, as plantas medicinais parecem ser alternativas bastante efetivas, de baixo custo e que apresentam poucos efeitos colaterais quando comparados à TRH.

\section{FINANCIAMENTO}

O presente trabalho foi realizado com apoio da Coordenação de Aperfeiçoamento de Pessoal de Nível Superior - Brasil (CAPES) - Código de Financiamento no 88887.192149/2018-00."

\section{REFERÊNCIAS}

1. BRASIL. Expectativa de vida do brasileiro sobe para 75,8 anos. 2017. Disponível em: https://agenciadenoticias.ibge.gov.br/agencianoticias/2012-agencia-de-noticias/noticias/18469-expectativa-de-vidado-brasileiro-sobe-para-75-8-anos.html .

2. SCHOENAKER, D. A. et al. Socioeconomic position, lifestyle factors and age at natural menopause: a systematic review and meta-analyses of studies across six continents. Int. J. Epidemiol., London, v. 43, n. 5, p. 1.542-1.562, Oct. 2014.

3. MIQUEL, J. et al. Menopause: a review on the role of oxygen stress and favorable effects of dietary antioxidants. Arch. Gerontol. Geriatr., Amsterdam, v. 42, n. 3, p. 289-306, May/June 2006.

4. ARTEAGA URZÚA, E. Menopausia y riesgo cardiovascular. Rev. Méd. Chile, Santiago, v. 144, p. 1.375-1.376, 2016. ISSN 0034-9887.
5. LORENZI, D. R. S. D. et al. Assistência à mulher climatérica: novos paradigmas. Rev. Bras. Enferm., Brasília, v. 62, p. 287-293, 2009.

6. SPANGENBURG, E. E.; JACKSON, K. C. The contribution of ovarian hormones to the cellular regulation of lipid metabolism. New York, 2013. p. 53-66. ISBN: 978-1-4614-8629-9.

7. OK, H. M. et al. A Root-based combination supplement containing pueraria lobata and rehmannia glutinosa and exercise preserve bone mass in ovariectomized rats fed a high-fat diet. Calcif. Tissue Int., Berlin, v. 97, n. 6, p. 624-633, Dec 2015. ISSN 0171-967x.

8. JUNIOR, V. F. V.; PINTO, A. C.; MACIEL, M. A. M. Plantas medicinais: cura segura? Química Nova, São Paulo, v. 28, n. 3, 2005.

9. WELFARE, A. I. O. H. A. Leading underlying causes of death by sex in Australia. 2014.

10. LOBO, R. A. et al. Prevention of diseases after menopause. Climacteric, London, v. 17, n. 5, p. 540-556, Oct 2014.

11. D'AMELIO, P. et al. Spontaneous osteoclast formation from peripheral blood mononuclear cells in postmenopausal osteoporosis. FASEB j., Bethesda, v. 19, n. 3, p. 410-412, Mar. 2005. ISSN 0892-6638.

12. RIGGS, B. L. et al. Changes in bone mineral density of the proximal femur and spine with aging. Differences between the postmenopausal and senile osteoporosis syndromes. J. Clin. Invest., New York, v. 70, n. 4, p. 716-723, Oct 1982.

13. WAUGH, E. J. et al. Risk factors for low bone mass in healthy 40-60 year old women: a systematic review of the literature. Osteoporos Int., [s.l.], v. 20, n. 1, p. 1-21, Jan. 2009.

14. KUSHWAHA, P. et al. A neoflavonoid dalsissooal isolated from heartwood of dalbergia sissoo roxb. has bone forming effects in mice model for osteoporosis. Eur. J. Pharmacol., Amsterdam, v. 788, p. 6574, Oct. 2016.

15. MOHD EFFENDY, N. et al. Time and dose-dependent effects of Labisia pumila on the bone strength of postmenopausal osteoporosis rat model. BMC complement. altern. med., London, v. 15, p. 58-58, 2015. ISSN: 1472-6882.

16. SUTHON, S. et al. Anti-osteoporotic effects of Pueraria candollei var. mirifica on bone mineral density and histomorphometry in estrogendeficient rats. J. Nat. Med., [s.I.], v. 70, n. 2, p. 225-233, Apr 2016.

17. $\mathrm{CHO}, \mathrm{H}$. J. et al. Effects of artemisia princeps supplementation on bone metabolism in ovariectomized rats. J. Nutr. Health Aging, New York, v. 20, n. 5, p. 533-539, 2016.

18. MUTHUSAMI, S. et al. Cissus quadrangularis prevented the ovariectomy induced oxidative stress in the femur of adult albino rats. Biomed. Pharmacother., Paris, v. 81, p. 416-423, July 2016.

19. KHEDGIKAR, V. et al. Preventive effects of withaferin A isolated from the leaves of an Indian medicinal plant Withania somnifera (L.): comparisons with 17-beta-estradiol and alendronate. Nutrition, [s.I.], v. 31, n. 1, p. 205-213, Jan 2015.

20. LIZCANO, F.; GUZMAN, G. Estrogen deficiency and the origin of obesity during menopause. Biomed. Res. Int., [s.I.], v. 2014, p. 757.461, 2014.

21. YUNG, L. M. et al. Chronic cranberry juice consumption restores cholesterol profiles and improves endothelial function in ovariectomized rats. Eur. J. Nutr., London, v. 52, n. 3, p. 1.145-1.155, Apr. 2013.

22. ZHANG, J. M. et al. Danshen enhanced the estrogenic effects of Qing E formula in ovariectomized rats. BMC Complement. Altern. Med., London, v. 16, p. 181, June 2016. ISSN 1472-6882. 
23. KIM, J. et al. Inhibitory effects of Leonurus sibiricus on weight gain after menopause in ovariectomized and high-fat diet-fed mice. J. Nat. Med., Tokyo, v. 70, n. 3, p. 522-530, July 2016.

24. LEE, J. E. et al. Polygonatum stenophyllum improves menopausal obesity via regulation of lipolysis-related enzymes. J. Nat. Med., Tokyo, v. 70 , n. 4, p. 789-796, Oct 2016.

25. IBRAHIM, R. M. et al. A randomised controlled trial on hypolipidemic effects of Nigella Sativa seeds powder in menopausal women. J. Transl. Med., London, v. 12, p. 82-82, 2014.

26. HIRAKI, E. et al. Anti-obesity activity of Yamabushitake (Hericium erinaceus) powder in ovariectomized mice, and its potentially active compounds. J. Nat. Med., Tokyo, v. 71, n. 3, p. 482-491, July 2017.

27. YANG, H. J. et al. The combination of Artemisia princeps Pamp, Leonurus japonicas Houtt, and Gardenia jasminoides Ellis fruit attenuates the exacerbation of energy, lipid, and glucose by increasing hepatic PGC-1alpha expression in estrogen-deficient rats. BMC Complement. Altern. Med., London, v. 16, p. 137, May 232016.

28. GARCIA-VILLALBA, R. et al. Bioavailability of phenolics from an oleuropein-rich olive (Olea europaea) leaf extract and its acute effect on plasma antioxidant status: comparison between pre - and postmenopausal women. Eur. J. Nutr., Darmstadt, v. 53, n. 4, p. 1.0151.027, June 2014.

29. POZZI, S. et al. Estrogen action in neuroprotection and brain inflammation. Ann. N. Y. Acad. Sci, New York, v. 1.089, p. 302-323, Nov 2006.

30. XU, J. et al. Effects of genistein on hippocampal neurodegeneration of ovariectomized rats. J. Mol. Neurosci., Totowa, v. 31, n. 2, p. 101-12, 2007.

31. LIU, B.Y. et al. Buyang Huanwu Decoction (补阳还五汤) reduces infarct volume and enhances estradiol and estradiol receptor concentration in ovariectomized rats after middle cerebral artery occlusion. Chin. J. Integr. Med., Beijing, v. 20, n. 10, p. 782-786, Jan. 2014.

32. MONTHAKANTIRAT, O. et al. Effect of miroestrol on ovariectomyinduced cognitive impairment and lipid peroxidation in mouse brain. Phytomedicine, Stuttgart, v. 21, n. 11, p. 1.249-1.255, Sep 252014.

33. JEARAPONG, N.; CHATUPHONPRASERT, W.; JARUKAMJORN, K. Miroestrol, a phytoestrogen from Pueraria mirifica, improves the antioxidation state in the livers and uteri of beta-naphthoflavone-treated mice. J. Nat. Med., Tokyo, v. 68, n. 1, p. 173-180, Jan. 2014.

34. PARK, H. J. et al. Soyo-san reduces depressive-like behavior and proinflammatory cytokines in ovariectomized female rats. BMC
Complement. Altern. Med., London, v. 14, p. 34, Jan 212014.

35. KRONENBERG, F. Hot flashes: epidemiology and physiology. Ann. N. Y. Acad. Sci., New York, v. 592, p. 52-86, 1990.

36. GALLICCHIO, L. et al. Type of menopause, patterns of hormone therapy use, and hot flashes. Fertil Steril, New York, v. 85, n. 5, p. 14321440, May 2006.

37. WANG, S. W. et al. Ameliorating effect of Erxian decoction combined with Fructus Schisandrae chinensis (Wu Wei Zi) on menopausal sweating and serum hormone profiles in a rat model. Chin. med., London, v. 11, p. 47-47, 2016.

38. KASHANI, L. et al. Efficacy of Crocus sativus (saffron) in treatment of major depressive disorder associated with post-menopausal hot flashes: a double-blind, randomized, placebo-controlled trial. Arch. Gynecol. Obstet., Munchen, v. 297, n. 3, p. 717-724, Mar. 2018.

39. ZINGUE, S. et al. Estrogenic and cytotoxic potentials of compounds isolated from Millettia macrophylla Benth (Fabaceae): towards a better understanding of its underlying mechanisms. BMC Complement. Altern. Med., London, v. 16, n. 1, p. 421, 2016/10/26 2016.

40. AMERICAN HEART, A. et al. Diagnosis and management of the metabolic syndrome. An American Heart Association/National Heart, Lung, and Blood Institute Scientific Statement. Executive summary. Cardiol. Rev., Hagerstown, v. 13, n. 6, p. 322-7, Nov-Dec 2005.

41. ABEDI, P. et al. Effect of fennel vaginal cream on sexual function in postmenopausal women: a double blind randomized controlled trial. J. Med. Life, [s.I.], v. 11, n. 1, p. 24-28, Jan./Mar. 2018.

42. YARALIZADEH, M. et al. Effect of Foeniculum vulgare (fennel) vaginal cream on vaginal atrophy in postmenopausal women: A double-blind randomized placebo-controlled trial. Maturitas, Limerick, v. 84, p. 7580, Feb. 2016.

43. RAHIMIKIAN, F. et al. Effect of Foeniculum vulgare Mill. (fennel) on menopausal symptoms in postmenopausal women: a randomized, triple-blind, placebo-controlled trial. Menopause, New York, v. 24, n. 9, p. 1.017-1.021, Sept. 2017.

44. ZINGUE, S. et al. Estrogenic effects of Ficus umbellata Vahl. (Moraceae) extracts and their ability to alleviate some menopausal symptoms induced by ovariectomy in Wistar rats. J. Ethnopharmacol., Limerick, v. 179, p. 332-44, Feb. 172016.

45. ZINGUE, S. et al. Estrogen-like and tissue-selective effects of 7-methoxycoumarin from Ficus umbellata (Moraceae): an in vitro and in vivo study. BMC Complement. Altern. Med., London, v. 17, n. 1, p. 383, Aug. 2017.

Submetido em: $22 / 10 / 2019$

Aceito em: 18/02/2020 